OPEN ACCESS

Edited by:

Celio Geraldo Freire-de-Lima, Universidade Federal do Rio

de Janeiro, Brazil

Reviewed by:

Juan Diego Maya,

Universidad de Chile, Chile

Manuel Soto,

Universidad Autonoma de Madrid,

Spain

*Correspondence: Fatima Conceição-Silva fconcei@ioc.fiocruz.br

Specialty section: This article was submitted to Microbial Immunology, a section of the journal

Frontiers in Microbiology

Received: 27 March 2018

Accepted: 29 May 2018

Published: 19 June 2018

Citation:

Conceição-Silva F, Leite-Silva J and

Morgado FN (2018) The Binomial Parasite-Host Immunity in the Healing Process and in Reactivation of Human Tegumentary Leishmaniasis.

Front. Microbiol. 9:1308 doi: 10.3389/fmicb.2018.01308

\section{The Binomial Parasite-Host Immunity in the Healing Process and in Reactivation of Human Tegumentary Leishmaniasis}

\author{
Fatima Conceição-Silva $^{1 *}$, Jessica Leite-Silva ${ }^{1}$ and Fernanda N. Morgado ${ }^{2}$ \\ ${ }^{1}$ Laboratory of Immunoparasitology, Oswaldo Cruz Institute (Fiocruz), Rio de Janeiro, Brazil, ${ }^{2}$ Laboratory of Leishmaniasis \\ Research, Oswaldo Cruz Institute (Fiocruz), Rio de Janeiro, Brazil
}

Leishmaniasis is a vector-borne infectious disease caused by different species of protozoa from the Leishmania genus. Classically, the disease can be classified into two main clinical forms: Visceral $(\mathrm{VL})$ and Tegumentary $(\mathrm{TL})$ leishmaniasis. $\mathrm{TL}$ is a skin/mucosal granulomatous disease that manifests mainly as cutaneous localized or disseminated ulcers, papules diffusely distributed, mucosal lesions or atypical lesions. Once the etiology of the infection is confirmed, treatment can take place, and different drugs can be administered. It has already been shown that, even when the scar is clinically evident, inflammation is still present in the native tissue, and the decrease of the inflammatory process occurs slowly during the 1st years after clinical healing. The maintenance of residual parasites in the scar tissue is also well documented. Therefore, it is no longer a surprise that, under some circumstances, therapeutic failure and/or lesion reactivation occurs. All over the years, an impressive amount of data on relapses, treatment resistance and lesion reactivation after healing has been collected, and several factors have been pointed out as having a role in the process. Different factors such as Leishmania species, parasite variability, Leishmania RNA virus 1, parasite load, parasite persistence, age, nutritional status, gender, co-morbidities, co-infection, pregnancy, immunosuppression, lesion duration, number and localization of lesions, drug metabolism, irregular treatment and individual host cellular immune response were described and discussed in the present review. Unfortunately, despite this amount of information, a conclusive understanding remains under construction. In addition, multifactorial influence cannot be discarded. In this context, knowing why leishmaniasis has been difficult to treat and control can help the development of new approaches, such as drugs and immunotherapy in order to improve healing maintenance. In this sense, we would like to highlight some of the findings that may influence the course of Leishmania infection and the therapeutic response, with an emphasis on TL.

Keywords: tegumentary leishmaniasis, healing process, lesion reactivation, patients, leishmaniasis, Leishmania parasites, co-morbidities, immunosuppression 


\section{THE PROBLEM}

Leishmaniasis is a vector-borne infectious disease caused by different species of the Leishmania genus. Classically, the disease is classified into two main clinical forms: Visceral (VL) and Tegumentary (TL) leishmaniasis. Although VL is more severe, TL is much more spread all over the world. According to the World Health Organization (WHO), cases of leishmaniasis can be found in 98 countries with approximately $0.7-1$ million cases of TL and 200-400 thousand cases of VL per year (Alvar et al., 2012; World Health Organization [WHO], 2017a).

Tegumentary leishmaniasis is a skin/mucosal granulomatous disease that manifests as cutaneous localized or disseminated ulcers, papules diffusely distributed, mucosal lesions or atypical lesions (Table 1) (Marzochi and Marzochi, 1994; AzeredoCoutinho et al., 2007; Kevric et al., 2015; Reis et al., 2016; Brazil, 2017; Carvalho et al., 2017). Marzochi and Marzochi (1994) suggested a clinical approach based on clinical and evolutionary aspects as follow: (1) Localized cutaneous leishmaniasis (LCL), most commonly manifestation of tegumentary leishmaniasis, it is characterized by single or multiple ulcers with varying measures of $\mathrm{mm}$ to $\mathrm{cm}$. In most cases, it is located in exposed areas and at the site of inoculation of the parasite. The typical ulcer is painless, of varied size, has delimited and raised edges of granular bottom. These lesions may regress spontaneously after some time (Costa et al., 1987; Oliveira-Ribeiro et al., 2017) or by use of specific therapies. The scar, in general, has a smooth, thin, shiny and hypopigmented appearance (Figure 1A) (Costa et al., 1987; Schubach et al., 1998). Cases of reactivation of the lesions can be seen in some patients considered clinically cured (Figure 1B). (2) Disseminated Cutaneous Leishmaniasis (DiL), it is considered one of the rare forms of the disease, characterized mainly by the large number of lesions found by the body ranging from ten to even hundreds (Machado et al., 2011). It initially presents an ulcer similar to the localized cutaneous form and evolves with the appearance of several polymorphic papules, that may have acneiform, nodular, ulcerated, verrucous and plaque appearance. (3) Diffuse Cutaneous Leishmaniasis (DCL), it is a rare form of ATL with multiple non-ulcerated nodular lesions, usually presenting a verrucous, plaque and/or vegetative aspect reaching large body regions. Patients affected by the diffuse form have no cellular immune response to Leishmania spp. antigens (Convit et al., 1972), with a Montenegro skin test (MST) negative and a poor response to therapies. (4) Mucosal Leishmaniasis (ML), it is considered serious and usually appears years after the skin lesion, affecting mucous membranes of the nose, mouth, pharynx, and larynx, causing irreversible destructive lesions that can lead to respiratory complications and malnutrition. It is estimated that 3-5\% of cases of cutaneous form develop mucosal lesion (Marzochi and Marzochi, 1994; Azeredo-Coutinho and Mendonça, 2014; Brazil, 2017).

Other less common clinical presentations are described. As such, we can cite the a so-called leishmaniasis recidiva cutis (LRC), which consists of repeated reactivation of lesions around

TABLE 1 | Clinical characteristics of lesions and the Leishmania species involved in main clinical forms of TL.

\begin{tabular}{|c|c|c|c|}
\hline Geographic distribution & Main species & TL clinical forms & Lesion description \\
\hline New World & $\begin{array}{l}\text { L. N.) braziliensis L. (L.) amazonensis } \\
\text { L. V.) guyanensis L. (L.) mexicana L. } \\
\text { V.) panamensis L. (V.) lainsoni }\end{array}$ & $\begin{array}{l}\text { Localized cutaneous } \\
\text { leishmaniasis (LCL) }\end{array}$ & $\begin{array}{l}\text { Single or multiple ulcerated lesions located in a single region of } \\
\text { the body. The typical ulcer is painless, of varied size, well } \\
\text { delimited with raised infiltrated edges and granular bottom, and } \\
\text { usually with good response to treatment. }\end{array}$ \\
\hline
\end{tabular}

\section{Old World}

New World

New World

L. (L.) amazonesis L. (L.) mexicana

\section{Old World}

New World

Old World

New World

Old World

L. (L.) major L. (L.) tropica L. (L.) aethiopica
L. (V.) braziliensis L. (L.) amazonenses

Disseminated leishmaniasis (DiL)

Diffuse cutaneous leishmaniasis (DCL)

Leishmaniasis recidiva cútis (LRC)

Mucocutaneous leishmaniasis $(\mathrm{ML})$

Late $\mathrm{ML}$

Concurrent ML

Contiguous ML

ML of undetermined origin
Numerous lesions ( $\geq 10$ ), most of them small and ulcerated, distant from the site of the phlebotomine bite. Good/poor response to treatment.

Rare form of ATL with multiple non-ulcerated infiltrated or nodular lesions reaching large body regions, usually presenting a plaque, verrucous and/or vegetative aspect.

Repeated reactivation of lesions around or within the scar of the classic cutaneous form of leishmaniasis.

Affects mucous membranes of the nose, mouth, pharynx and/or larynx, causing destructive lesions (mainly ulcer with infiltration) that can lead to respiratory complications and malnutrition. Prolonged treatment is usually effective.

Mucous membranes lesions occur months or years after cutaneous lesions.

Occurrence of simultaneous cutaneous and mucosal lesions. Mucosal lesions developed by contiguity due to the presence of periorificial cutaneous lesions on the face.

Mucous membranes lesions without any active cutaneous lesion or compatible scar or history of previous leishmaniasis cutaneous lesion. 

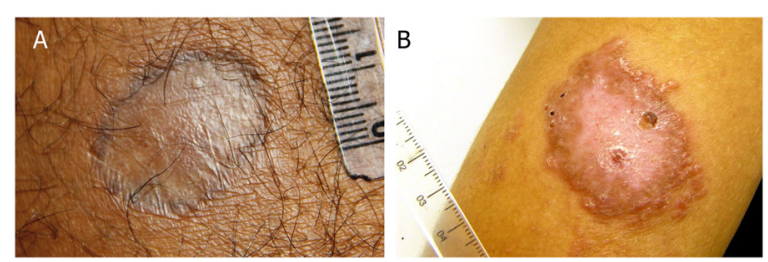

FIGURE 1 | Tegumentary leishmaniasis caused by Leishmania braziliensis. (A) Atrophic scar post a successful treatment; (B) lesion reactivation post treatment. Photos kindly provided by Dr. M. R. Lyra and LaPClin Vigileish National Institute of Infectology Evandro Chagas -INI- Fiocruz.

or within the scar of the classic cutaneous form of leishmaniasis (Bittencourt et al., 1993; Oliveira-Neto et al., 1998). The genesis of these different clinical presentations, ranging from single cutaneous lesions with self-limited evolution and tendency to spontaneous healing, to widespread forms that often evolve with difficult treatment and control, has been related to different factors such as parasite species, patient nutrition and health status, number and localization of lesions, as well as an individual host cellular immune response (Silveira et al., 2004; Brazil, 2017). For example, some authors have shown that American tegumentary leishmaniasis (ATL) lesions located in the lower limbs need more time to heal (Oliveira-Neto et al., 1996; Schubach et al., 2005; Oliveira-Ribeiro et al., 2017). It has also been described that early treatment of ATL does not prevent ulcer development (Machado et al., 2002; Unger et al., 2009) and linked to higher rates of therapeutic failure (Unger et al., 2009). In this context, it has recently been verified that short evolution time and Montenegro skin test (MST) with low positivity were associated with cases of therapeutic failure (Antonio et al., 2014).

Once the etiology of the infection is confirmed, treatment can take place, and different drugs can be administered. In Brazil, the most common treatment is an intramuscular or intravenous injection of pentavalent antimonials (Brazil, 2017). In other world regions, amphotericin B, among other possibilities, is also designed to treat leishmaniasis (Tuon et al., 2008; PAHO, 2013; World Health Organization [WHO], 2017a). However, in addition to the well documented potential harmful toxicity of all drugs already described, increased information about resistance to the first and second choice drugs has highlighted the need for new drugs to treat leishmaniasis. But, until now it has not been possible to accomplish a new treatment with less toxicity and at least the same efficacy of the old available drugs. It is important to note that, in parallel to treatment failure, the literature has also evidenced the possibility of an early spontaneous healing without treatment (Oliveira-Ribeiro et al., 2017; Costa et al., 2018). In this context, understanding why leishmaniasis is becoming difficult to treat and control can help to develop new approaches to improve the healing of this infection. Unfortunately, despite an impressive amount of information, a conclusive understanding is still under construction. Our objective is to introduce and discuss some of the information already published regarding the factors that could influence the treatment response in humans with TL. Table 2 summarizes some findings regarding treatment response.

\section{THE HEALING PROCESS IN TL}

The presence of a balanced immune response mainly produced by cellular immunity is pointed out as necessary to control parasites and promote wound healing.

Due to difficulties in obtaining tissue smears, many studies have been focused on analyzing the peripheral blood immune response. It is important to note that relevant information has been described correlating the results of the evolution and severity of the lesions, as well as in the therapeutic response. Despite this, in the last years various results were obtained by the evaluation of tissue damages and the organization and activity of

TABLE 2 | Summary of the aspects involved in human TL treatment.

\section{Findings about treatment}

Cases of resistance to meglumine antimoniate have been increasing over the years

The parasite species, nutrition and health status of the patient, number and location of the lesions, and the cellular immune response of the host can influence the response to treatment

The early treatment of ATL does not prevent ulcer development A short evolution time and Montenegro skin test (MST) with low positivity were associated with cases of therapeutic failure

The literature has also evidenced the possibility of an early spontaneous healing without treatment

In cases of contraindication or resistance to pentavalent antimony, other drugs such as amphotericin B and pentamidine may be used. In some regions and species of Leishmania, these drugs are recommended as first choice because they are more effective than antimonials.

\section{Reference*}

Santos et al., 2002; Rodrigues et al., 2006; Rojas et al., 2006; Tuon et al., 2008; Oliveira et al., 2011; Lindoso et al., 2012; Schubach and Conceição-Silva, 2014; Ponte-Sucre et al., 2017; Vanaerschot et al., 2018 Oliveira-Neto et al., 1996, Oliveira et al., 2013; Faria et al., 2005; Machado-Coelho et al., 2005; Schubach et al., 2005; Morgado et al., 2008, 2015; Chiheb et al., 2012; Ibrahim et al., 2013; Cunha et al., 2015; Azeredo-Coutinho et al., 2016; García-Bustos et al., 2016; Oliveira-Ribeiro et al., 2017; Brazil, 2017; World Health Organization [WHO], 2017b

Machado et al., 2002; Unger et al., 2009

Convit et al., 1972; Antonio et al., 2014

Costa et al., 1987, 2018; Oliveira-Ribeiro et al., 2017

Ameen, 2010; Oliveira et al., 2011; Schubach and Conceição-Silva, 2014; Mosimann et al., 2018

* The literature on aspects of TL treatment is vast and other articles can be found. Here are just a few. 
the inflammatory process, which brought valuable information. Nylén and Eidsmo (2012) published a review addressing the different organizations of the inflammatory reaction in the different types of TL lesions. Other reviews have previously been published, bringing valuable information to better understand the immune response in TL (Conceição-Silva et al., 2010; Oliveira et al., 2014; Scott and Novais, 2016; Rossi and Fasel, 2018; among others). The involvement of the in situ inflammatory response in the formation and maintenance of the lesions has previously been demonstrated in the murine model. In this context, Belkaid et al. (2000) demonstrated in the murine infection that the formation of the ulcer is almost due to the inflammatory process, and not necessarily to the increase in parasite number, since the ulceration arises when the inflammatory process begins to settle and at the same point the parasitic load tends to decrease. In addition, in patients, the balance between types 1 and 2 responses has been identified as a determinant in the evolution of TL to self-limited or severe forms (Awasthi et al., 2004; Gollob et al., 2008).

The typical immune response detected in localized cutaneous leishmaniasis patients (LCL) is characterized by the production of proinflammatory cytokines, predominantly Th1 cytokines, such as INF- $\gamma$, interleukin (IL) -2 and TNF (Da-Cruz et al., 1996; Gaafar et al., 1999; Coutinho et al., 2002; Gomes-Silva et al., 2007; Kima and Soong, 2013). However, the regulatory response of type 2 cytokines is also presented in the LCL form, by the production of IL-4, IL-5, IL-13, and TGF- $\beta$. It is known that an exaggerated Th1 response can lead to tissue damage and has been associated with the immunopathogenesis of mucosal lesions (Ribeiro-deJesus et al., 1998; Bacellar et al., 2002; Faria et al., 2005; Palmeiro et al., 2012). Thus, type 1 balanced response with production of cytokines such as IFN- $\gamma$, IL-12, and TNF is indispensable for the control of Leishmania spp. infection (Nylén and Eidsmo, 2012; Souza et al., 2012; Scott and Novais, 2016). A summary of the main immunological features already described in the tegumentary leishmaniasis is represented in Figure 2.
Concerning the tissue microenvironment, it has also been shown that ATL lesions are characterized by a chronic granulomatous inflammatory reaction, with intense lymphoplasmacytic infiltration (Quintella et al., 2012). Lymphocytes, macrophages and neutrophils predominate in the lesions of typical LCL, defined as those with the presence of ulcers with infiltrated borders and granular bottoms (Schubach et al., 2005). Morgado et al. (2008) verified that the inflammatory process was similar in lesions with both, shorter and longer time of evolution, including neutrophils in all patients studied. However, the dynamics of the cellular infiltrate was modified and in the lesions with more than 6 months of evolution it was possible to identify a gradual decrease of $\mathrm{CD}^{+} \mathrm{T}$ cells and increase of $\mathrm{CD}^{+}{ }^{+} \mathrm{T}$ cells associated with the beginning of the healing process and tendency to focal inflammation permeated by areas of fibrosis. These changes could be linked to decreased parasite load (Morgado et al., 2008) and local control of immunological effectors by the accumulation of Treg cells (Campanelli et al., 2006). In this sense, the accumulation of Treg cells, IL-10 and TGF- $\beta$ in late lesions was also observed (Hejazi et al., 2012; Hoseini et al., 2014). On the other hand, the imbalanced response can both decrease and exacerbate type 1 response that can elicit tissue damage making difficult to control TL. In this context, Maspi et al. (2016) suggested that an immune response with predominance of Type 2 cytokines (IL-4, IL-5) and IL-10 may decrease the expression of the nitric oxide synthase- 2 (NOS2) enzyme resulting in insufficient macrophage stimulation to its parasiticide stage, aiding parasitic proliferation and leading to an increase in disease severity as well as to a difficult treatment, as observed in diffuse cutaneous leishmaniasis. Mucosal lesions have been proposed to have an exacerbated and imbalanced cellular immune response with significant increase in lymphocytes, macrophages, Th1 cytokines such as IFN- $\gamma$ as well as NO (Gomes-Silva et al., 2007; Palmeiro et al., 2012). When compared to cutaneous leishmaniasis, mucosal lesions presented

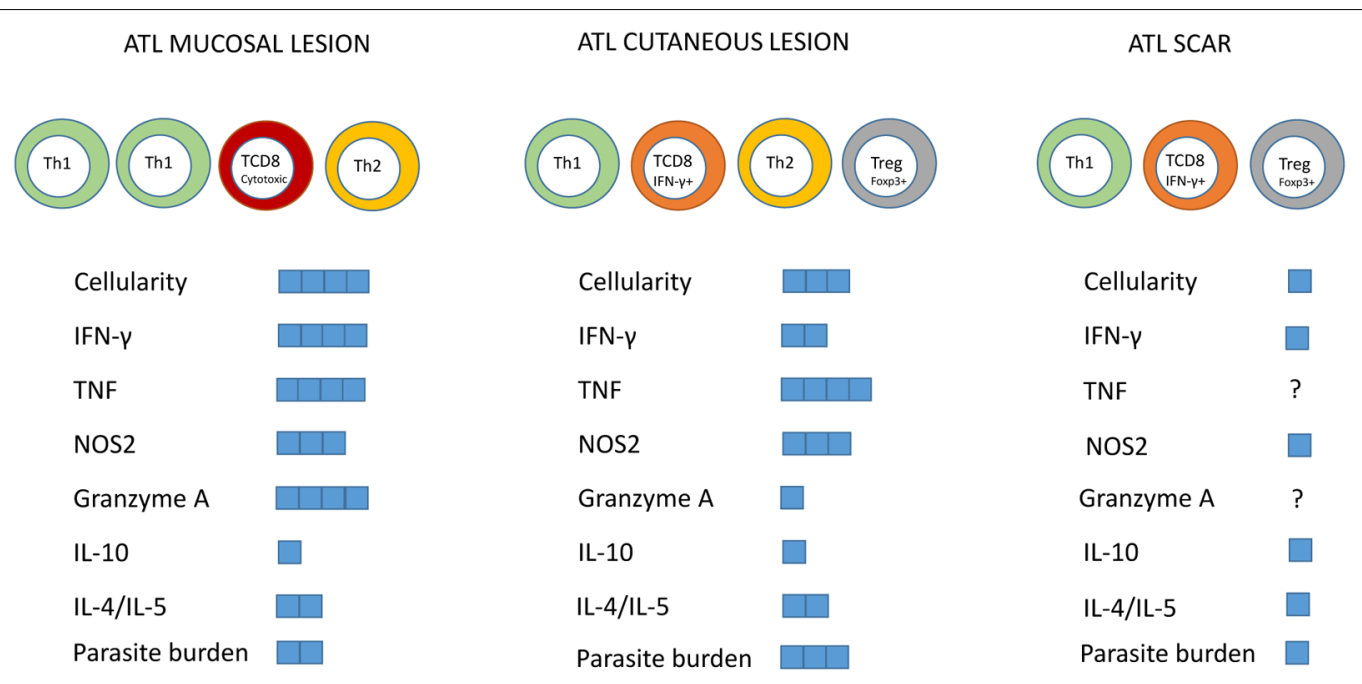

FIGURE 2 | Summary of the main immunological features described in mucosal lesions, localized cutaneous leishmaniasis and skin scars of tegumentary leishmaniasis. Predominant cell subtypes were indicated for each clinical form. The blue squares represent the intensity of the parameters indicated in the figure. 
similar amounts of IL-10, NOS2, and TNF, and higher IFN- $\gamma$ and granzyme A expression accompanied by reduced IL-10 receptor expression (Faria et al., 2005). This uncontrolled response could be responsible for the significant tissue damage, explaining the appearance of extensive, destructive, and difficult-to-treat lesions.

The detailing of the immune response involved in the formation of TL lesions has been the subject of numerous revisions, but some details are important for understanding the mechanism of cure or therapeutic failure. In this context, other cells participate in the inflammatory process and may influence the progression of TL lesions and some have been implicated as involved in both, the control and the pathogenesis of the infection. $\mathrm{CD}^{+} \mathrm{T}$ cells are considered important components of the inflammatory infiltrate present in the lesions (Faria et al., 2009; Santos et al., 2013). However, its function has been discussed and recently it has been demonstrated that according to the functional profile, $\mathrm{CD}^{+} \mathrm{T}$ cells could play a beneficial (increasing the supply of IFN- $\gamma$ ) or harmful (by the predominance of cytotoxic activity) role (Novais and Scott, 2015; Novais et al., 2018). Neutrophils have also been involved in the decrease in parasite load or in the amplification of macrophage infection (Tacchini-Cottier et al., 2000; John and Hunter, 2008; Conceição et al., 2016). In this context, our group identified the presence of neutrophils in lesions with different time of evolution (Morgado et al., 2008). It was also verified that Leishmania spp. induces neutrophil extracellular trap (NET) formation in a parasite load dependence and the leishmanicidal activity of NET was verified in vitro (Guimarães-Costa et al., 2009). NET formation was also identified in active lesions of ATL and the presence of two predominant NET sizes related to parasite load was demonstrated (Morgado et al., 2015). Other studies have shown the influence of different cytokines such as IL-17 and enzymes such as arginase in the pathogenesis of TL (Soong et al., 2012; Rath et al., 2014; Banerjee et al., 2016, among others). Although in part these immunological mechanisms together can reduce the local parasite load, Leishmania is able to escape from immune effectors then persisting in the lesion site (Makala et al., 2011; Guimarães-Costa et al., 2014). For example, Leishmania spp. can escape in vitro from the NET-mediated killing through $3^{\prime}$-nucleotidase/nuclease activity (Guimarães-Costa et al., 2014). In fact, intact amastigotes surrounded by NETs were previously observed in active lesions from ATL patients (Morgado et al., 2015).

Skin inflammation also plays an important role during the healing of ATL and parasite antigens in ATL scars have already been reported (Schubach et al., 1998; Mendonça et al., 2004; Morgado et al., 2010). In situ evaluation of LCL scars demonstrated that after 1 year from healing, the scars presented inflammatory nests surrounded by scar tissue as well as close to vessels and cutaneous glands. Inflammatory areas presented similar organization than that observed in active lesions from the same patient, including number and distribution of lymphocytes and macrophages, despite a reduction in the inflammatory areas. When scars were examined after 3 year evolution, it was still possible to verify that the inflammatory foci were still present and showing signs of inflammatory activity, including the detection of parasites, but presenting lower cellularity as compared with 1 year scars (Morgado et al., 2010). These results pointed out that the cellular composition of the skin inflammatory reaction changes steadily even after wound healing and, along with the presence of parasites suggests a dynamic balance between parasite multiplication and immune response that could be disrupted in some situations. Thus, individuals with persistent parasites may present disease recurrences (Saravia et al., 1990). In addition, the parasitic persistence may contribute to the continuous immune system stimulation, maintaining a pool of Leishmania -specific effector cells which can be detected in peripheral blood of healed patients (Gaafar et al., 1999; Lakhal-Naouar et al., 2015), inducing a protective action (Pereira-Carvalho et al., 2013). The implications of parasite persistence on TL scars become important for the explanation of cases of reactivation of infection, years after clinical cure and will be discussed later in this review.

In the LCL, the cure criterion is clinical and can be defined as healing with complete re-epithelialization, disappearance of crusts, flattening of the borders of the lesions and absence of new lesions (Lindoso et al., 2012; PAHO, 2013), as well as erythema reduction within 3 months of the therapeutic regimen. The healing of the mucosal lesion must be confirmed by otorhinolaryngological examination, until 6 months after the end of the treatment (Gontijo and Carvalho, 2003). In both situations, it is important to monitor the patient at least up to 12 months after clinical cure for early detection of signs of lesion reactivation. Such signs are the absence of complete epithelization until 90 days after the first course of treatment, as well as the worsening of clinical condition and/or the presence of additional lesions. In these cases, the Brazilian Health Ministry recommends a second treatment regimen (Brazil, 2017). It is important to emphasize that, during monitoring, recurrence, therapeutic failure and disease reactivation can be observed. Thus, some authors believe that confirmation of clinical cure is not always satisfactory, due to the occurrence of numerous reports of recurrence even after therapy and total wound healing. It would be interesting to be able to standardize healing criteria not only in relation to clinical parameters, but also parasitological and therapeutic.

\section{WHY PATIENTS ARE NOT ALWAYS HEALED?}

All over the years, an impressive amount of information has been collected. As consequence, several factors have been implicated as having a role in the process of treatment failure and/or disease reactivation even several years after the clinical cure and it is not possible to discard a multifactorial influence in the response to the specific treatment. Different factors such as Leishmania species (Handler et al., 2015), genetic background, age, weight, co-morbidities, lesion duration, number and localization of lesions, drug metabolism, irregular treatment, among others were described (Vera et al., 2001; Rojas et al., 2006; Unger et al., 2009). In this sense, we would like to highlight some of the findings that may alter the course of Leishmania infection and modify the therapeutic response in leishmaniasis, with an emphasis on TL. 


\section{PARASITE POINT OF VIEW: DO PARASITES INFLUENCE THE THERAPEUTIC RESPONSE?}

\section{Parasite Variability}

The Leishmania sp. protozoa is considered one of the determining factors of the clinical manifestations (Handler et al., 2015). For example, in the New World the infection by Leishmania braziliensis produces localized ulcers whereas the infection by L. guyanensis can produces multiple lesions. L. naiffi, in general produces benign and auto-resolute lesions that heal spontaneously. Mucosal manifestations occur in patients infected by L. braziliensis and L. guyanensis, whereas diffuse leishmaniasis occurs in patients infected by L. amazonensis (Brazil, 2017). Coinfections with different Leishmania species have been described in patients from Manaus, Brazil (Camara-Coelho et al., 2011). However, the impact of co-infections by different Leishmania species still needs to be elucidated.

Molecular characterization of Leishmania isolates has been vastly carried out by four classical markers: the rRNA internal transcribed spacer 1 (ITS-1), kDNA minicircles, the heat shock protein 70 (HSP70) and the mitochondrial cytochrome b (Cyt-b) through techniques based on the digestion by restriction endonuclease enzymes and sequencing of amplified gene followed by phylogenetic analysis (Buitrago et al., 2011; Cruz et al., 2013; Koltas et al., 2016; Morgado et al., 2016; Bilbao-Ramos et al., 2017). These studies have shown the existence of different genotypes and their relation with clinical manifestations and susceptibility to leishmanicidal drugs. As consequence, disease control could be severely compromised by the intrinsic variability of the circulating species that may limit the efficacy of the treatment while favoring the emergence of resistance. For example, in a study of patients from Bolivia, L. braziliensis, L. lainsoni and a local variant of L. mexicana were isolated and showed differences in the susceptibility to drugs such as Fungizone ${ }^{\circledR}$, Glucantime ${ }^{\circledR}$ and Miltefosine (BilbaoRamos et al., 2017). L. braziliensis and L. mexicana showed moderate sensitivity to Glucantime ${ }^{\circledR}$, whereas L. lainsoni was not sensitive to Glucantime ${ }^{\circledR}$.

The different zimodemes detected in Leishmania (Viannia) isolates from Colombia was associated with clinical and epidemiological characteristics (Saravia et al., 1998). In another study using the randomly amplified polymorphic DNA technique, polymorphisms were detected in isolates from Brazilian patients (Schriefer et al., 2004). All forms of ATL presented a statistically significant difference in their frequencies among the clades, suggesting that L. braziliensis genotypes may be accompanied by specific disease manifestation after infection.

Marlow et al. (2014) evaluated 86 strains of L. braziliensis from Brazil and identified three populations named POP1, POP2, and POP3 through multilocus sequence analysis (MLSA). The authors observed a significant association between the genetic cluster and the clinical forms of patients. Most strains isolated from patients presenting mucocutaneous form belonged to POP3. Furthermore, $28.6 \%$ of strains belonging to POP3 were isolated from patients with mucocutaneous clinical form, whereas $3.1 \%$ belonging to POP1 and 5.9\% belonging to POP2 were isolated from mucocutaneous patients (Marlow et al., 2014).

\section{Leishmania RNA Virus 1 (LRV1)}

Still looking from the parasite side, recently, Leishmania RNA virus 1 (LRV1) was identified in isolates from South America and has been associated with the exacerbation of clinical presentations, mucosal lesion emergence and relapses (Cantanhêde et al., 2015; Bourreau et al., 2016; Tirera et al., 2017). LRV was associated to a variety of Leishmania species isolated from human patients such as L. guyanensis, L. braziliensis, L. aethiopica, L. major (Zangger et al., 2014; Cantanhêde et al., 2015; Adaui et al., 2016; Bourreau et al., 2016; Parmentier et al., 2016; Tirera et al., 2017). The immunological mechanisms behind the worsening of the disease are not fully understood but authors have pointed out the role of endogenous viruses like LRV1 in inducing the expression of type 1 interferon and down-regulation of IFN- $\gamma$ receptors by macrophages (Rossi and Fasel, 2018). The increase of type 1 interferon in mice leads to an increase in pathogenicity. Associated to the reduction of IFN- $\gamma$ signal, this profile is not able to fully control the parasite load. Some evidence showed the recognition of LRV1 by TLR3 receptor (Macedo et al., 2016) and consequent upregulation of miR-155 and the promotion of parasite persistence mediated by macrophage survival through akt activation (Eren et al., 2016). The blockade of akt or miR-155 deficiency showed a drastic decrease in LRV1-induced disease severity (Eren et al., 2016).

The presence of LRV1 was also investigated in patients infected with L. guyanensis (Bourreau et al., 2016). The authors showed significant prediction of treatment failure in positive cases. However, the presence of Leishmania RNA virus 1 infection cannot be considered as exclusively factor inducing severity of tegumentary leishmaniasis in Brazil as observed by Pereira et al. (2013). The authors studied patients from Rio de JaneiroBrazil, where no LRV1 was detected despite the presence of mucosal patients suggesting that other factors may influence the exacerbation of the disease and mucosal development (Pereira et al., 2013). In this context, the inflammatory response generated by exogenous viruses in mice co-infected with Leishmania parasites was demonstrated (Rossi and Fasel, 2018). Furthermore, differences in proteome, metabolome and virulence of isolates from cutaneous and mucosal sites in the same patients were previously observed (Alves-Ferreira et al., 2015). Differences in immune response from nasal and oral lesions were also observed (Palmeiro et al., 2012) Altogether these data suggest the role of particularities from different tissue compartments on the metabolic/physiological pressure on the selection of Leishmania clones reflecting in differential clinical manifestations. On the other hand, in areas where Leishmania parasites are considered quite homogeneous like Rio de Janeiro, Brazil, different clinical presentations and different degrees of treatment response can be observed, also pointing out that other factors should be involved to determine the evolution of TL (Baptista et al., 2009).

\section{Parasite Load}

Another point to consider is the influence of parasite load on infection control and consequently on the response to treatment. 
In the murine model it has been described that, depending on the parasite concentration used for the experimental infection, the immune response can be modified, producing self-limited or severe lesions (Bretscher et al., 1992; Hosken et al., 1995; Menon and Bretscher, 1996). Courret et al. (2003) compared intradermic inoculations with different numbers of L. major promastigotes varying from 10 to 1000 metacyclic promastigotes and observed that different from mice infected with 10 parasites, inoculations with 100 or 1000 parasites led to progressive lesions in most of infected animals, as well as the resistance to reinfection. In hamster model infected with L. braziliensis different concentrations of initial inocula and evaluated during 105 days post infection showed that the lesion emergence occurred early in animals infected with higher inocula concentration (Ribeiro-Romão et al., 2014). However, at the end of the experiment, IFN- $\gamma$ expression and parasite load were similar between groups, suggesting that immunomodulation takes place early during experimental infection (Ribeiro-Romão et al., 2014).

During the sand fly blood feeding, a mix of promastigotes and saliva is inoculated in the dermis. Some compounds such as promastigote secretory gel (PSG), sand fly saliva, among others, may lead to a better establishment of infection, favoring the parasite survival at the beginning of infection (Almeida et al., 2003; Gomes and Oliveira, 2012; Courtenay et al., 2017). Furthermore, the modulation of host immune response by sand fly saliva components has been verified (Lestinova et al., 2017).

Although studies on experimental infection showed initial inocula impacted on clinical course, the parasite burden detected in established lesion may not influence the therapeutic response since Pereira et al. (2017) demonstrated high parasitism in good responders when compared with the poor ones (Pereira et al., 2017). However, there was an increase in parasite burden with recurrent relapses which suggests a failure of the immune system in controlling the parasite replication (Pereira et al., 2017).

Summarizing, several evidence has pointed out the role of parasites in the outcome of the disease. However, as it is not observed in all cases, other factors such as the host immune response and comorbidities, among others, may play a role in both severity and treatment relapse in TL.

\section{THE HOST POINT OF VIEW}

\section{The Impact of Comorbidities on Clinical Manifestations}

Many host factors have been associated with the development of skin or mucosal lesions and worsening of TL, as well as the appearance of unusual clinical presentations of cutaneous leishmaniasis. For example, patients infected with L. major and affected by diabetes mellitus type I showed more extensive and vegetative lesions (Chiheb et al., 2012). In another study, an association of the nutritional status and clinical and therapeutical evolution in adults and the elderly with ATL was observed (Oliveira et al., 2013). In this study, the impairment in food intake due to the mucosal lesions led to a serum albumin depletion which impaired the healing of the lesions and affected the effectiveness of ATL treatment (Oliveira et al., 2013).

Malnutrition is classified in different forms as follows: (1) undernutrition (wasting, stunting, underweight), (2) inadequate vitamins or minerals, (3) overweight, (4) obesity, and (5) resulting diet-related non-communicable diseases (World Health Organization [WHO], 2017b). WHO estimates that 462 million adults are underweight, 155 million children are stunted and 17 million are severely wasted (World Health Organization [WHO], 2017b) and a considerable part of them is living in endemic areas of leishmaniasis in South America, Africa, and Asia. One among the first studies on the impact of nutritional status on the infection by dermotropic Leishmania species was conducted in 1979 using C57BL/6 mice and experimental infection with L. mexicana (Pérez et al., 1979). Well-nourished mice presented self-healing lesions, whereas protein malnourished animals had a progressive disease, an impairment of the immune response, characterized by depressed delayed hypersensitivity response and in vitro lymphocyte reactivity to Leishmania antigen, and failed to recover from L. mexicana infection (Pérez et al., 1979). In humans, an association between malnutrition and mucosal lesion development was reported (Machado-Coelho et al., 2005). The impact of malnutrition on the capacity of the immune system to respond to Leishmania spp. infection was also observed in a model of murine visceral leishmaniasis (Ibrahim et al., 2013). There, the authors showed that protein malnutrition affects the conduit systems of lymph nodes impacting the barrier function of the organ and consequently promoting parasite dissemination and replication (Ibrahim et al., 2013). In mice, malnutrition results in drastic dysregulation of $\mathrm{T}$ cells and cytokine expression and affects the cell-mediated immune response to L. infantum by altering $\mathrm{T}$ cell migration in the spleen and thymus (CuervoEscobar et al., 2014; Losada-Barragán et al., 2017). Although the mechanisms involved in the impairment of the immune response to visceral leishmaniasis in malnourished individuals are better described, they are still unknown for cutaneous leishmaniasis.

In a case-series study conducted in Argentina, 95 patients were evaluated and most of them were diagnosed as infected by L. braziliensis (García-Bustos et al., 2016). High prevalence of mucocutaneous cases (35.8\%) was detected and most patients with concomitant infectious pathologies, such as Chagas disease, toxoplasmosis, syphilis and others, presented the mucosal form of the disease (62.5\%) (García-Bustos et al., 2016). The association between comorbidities and mucosal lesion development was also observed in patients from Brazil (Cunha et al., 2015; Azeredo-Coutinho et al., 2016). Systemic arterial hypertension (58.6\%), cardiopathies (mainly cardiac failure) (34.5\%) and diabetes mellitus (24.1\%) were the most frequent comorbidities observed (Cunha et al., 2015). In addition, the presence of intestinal helminthiasis has been described as able to interfere in both, treatment response and wound closure, as well as the association with mucosal lesions (O’Neal et al., 2007; AzeredoCoutinho et al., 2016). However, conflicting results have likewise been published showing no influence of intestinal infection in the improvement of clinical outcome (Newlove et al., 2011). Difference in helminthes in genus/species as well as the intensity of infection could explain these differences. 


\section{Does Bacteria and Virus Co-infection Influence the Healing Process in LCL?}

Secondary bacterial infections in cutaneous lesions of leishmaniasis are very common and the most frequent bacterium observed is Staphylococcus aureus (Ziaie and Sadeghian, 2008; AlSamarai and AlObaidi, 2009; Layegh et al., 2015; García-Bustos et al., 2016; Antonio et al., 2017). In addition, Salgado et al. (2016) have shown diversity in bacteria isolates obtained from lesions and the contralateral healthy skin of the same patient. The knowledge of the impact of secondary bacterial infection on the healing of cutaneous lesions is controversial. Some results do not demonstrate a correlation between bacterial infection and time for wound conclusion in LCL. Layegh et al. (2015) described that the simultaneous treatment for microbial agents did not influence on the healing of cutaneous lesions. Antonio et al. (2017) showed that the presence of secretion and burning sensation produced by bacterial infection influenced epithelization but not the total healing time. On the other hand, several authors have demonstrated the influence of secondary bacterial infections on lesion development and healing delay (Vera et al., 2001; Ziaie and Sadeghian, 2008; Sadeghian et al., 2011; García-Bustos et al., 2016). In this context, the maintenance of neutrophils in active lesions even with more than 4 months duration may be related to the stimulus generated by the persistent amastigotes but also to the presence of bacterial secondary infection (Morgado et al., 2008; Morgado et al., 2015). The inflammatory response to this secondary bacterial infection could hamper self-healing leading to the development of a chronic lesion.

Viruses can also be present in TL lesions. In this context, the impact of viral/Leishmania co-infections in pathogenesis was evaluated in a murine model infected with $L$. major and lymphocytic choriomeningitis virus (LCMV) (Crosby et al., 2015). They observed that infection with LCMV led to significantly enhanced disease in L. major-infected animals. This increased disease is correlated with an infiltration into the leishmanial lesions of $\mathrm{NKG}_{2} \mathrm{D}^{+} \mathrm{CD}^{+} \mathrm{T}$ cells producing granzyme B, but little IFN- $\gamma$ (Crosby et al., 2015). The depletion of $\mathrm{CD}^{+} \mathrm{T}$ cells after viral clearance, as well as blockade of NKG2D, reversed the increased pathology seen in co-infected mice. The authors demonstrated that even pathogens, known to promote a type 1 response, might exacerbate leishmanial infections (Crosby et al., 2015).

\section{Cutaneous Leishmaniasis in Extreme Ages}

Infants and the elderly share high vulnerability to infections (Vasconcellos et al., 2010; Lang et al., 2011). Although all age groups can be affected by cutaneous leishmaniasis, the most affected ones can vary from each region, from infants less than 9 years old to teenagers (aging 10-19 years) or adults (up to 45 years-old) (Aksoy et al., 2016; Brazil, 2017; Khezzani and Bouchemal, 2017). Therapeutic failure is frequently reported among children affected by cutaneous leishmaniasis (Rubiano et al., 2012; Castro et al., 2017), which could probably be associated with an immature immune system and consequently a failure in controlling the parasite load.
The increase in severity of cutaneous leishmaniasis was also associated with the aging (Machado-Coelho et al., 2005; Vasconcellos et al., 2010; Oliveira et al., 2013; Carvalho et al., 2015). Older patients had two-times more chances to develop mucosal lesions (Machado-Coelho et al., 2005). The reasons why elderly patients are more susceptible to severe manifestations are not fully elucidated. However, an increased number of comorbidities such as cardiomyopathy and diabetes mellitus, as well as the continuous use of medicines to treat them can partially explain it. It is also important to highlight the occurrence of immunological senescence (Weinberger et al., 2008), which reduces the capacity to produce cytokines such as IL-2 and IFN- $\gamma$ (Cillari et al., 1992) and the accumulation of functional regulatory $\mathrm{T}$ cells $\left(\mathrm{CD} 4^{+} \mathrm{FoxP}^{+} \mathrm{CTLA}-4^{+}\right)$which promote chronic infectious disease reactivation (Lages et al., 2008). Elderly persons have a decreased number of naive $T$ cells $\left(\mathrm{CD} 45 \mathrm{RA}^{+} \mathrm{CD} 28^{+}\right)$, which display significantly shorter telomeres and have a restricted TCR repertoire (Pfister et al., 2006). In them, the pool of naïve $B$ and $T$ cells is reduced because the bone marrow and thymus suffer from fat deposition impairing the production of new cells (Chambers and Goodell, 2007). Since $\mathrm{CD}^{+} \mathrm{T}$ cells are important to control the parasite load in cutaneous leishmaniasis (Bittar et al., 2007; Morgado et al., 2008, 2010; Pereira-Carvalho et al., 2013) this can explain the susceptibility of elderly patients to severe manifestations. Peripheral blood mononuclear cells from elderly patients infected with $L$. braziliensis produced less IFN- $\gamma$ and more IL-10 than the cells from young subjects (Carvalho et al., 2015). Altogether, these data point to the need to search mucosal or disseminated lesions in elderly patients presenting tegumentary leishmaniasis since they produce lower quantities of IFN- $\gamma$ and higher quantities of IL-10 than adult patients which may contribute to parasite persistence and L. braziliensis infection dissemination. In this context, in a case-series study conducted in Argentina, that included 95 patients diagnosed as infected by L. braziliensis (García-Bustos et al., 2016), the authors also detected an association between age and the development of mucosal lesions.

\section{Gender Differences in Cutaneous Leishmaniasis}

In the case-series study above mentioned, (García-Bustos et al., 2016), the authors also detected an association between gender and development of mucosal lesions. They observed a predominance of male and attributed it to their occupational activity since they were rural workers. Although other authors showed higher prevalence of male patients (Machado-Coelho et al., 2005; Giavedoni et al., 2015; Brazil, 2017), the opposite could also be observed (Aksoy et al., 2016). In fact, differences on the immune response profile between male and female animals have been reported (Satoskar et al., 1998; Travi et al., 2002). For example, male hamsters were described as presenting more severe disease and higher intralesional expression of IL-4, IL-10, and TGF- $\beta$ when compared to female animals (Travi et al., 2002). Furthermore, the Th1 response was more intense in female than male mice (Satoskar et al., 1998). Perhaps sex hormones play a role in the differences observed between genders in cutaneous 
leishmaniasis as previously observed (Baccan et al., 2011). In this context, in hamsters infected with L. panamensis, estrogen was associated to an up-regulation of NOS2 expression and nitric oxide (NO) production (Osorio et al., 2008) that could explain the higher resistance to severe lesions by women when compared to men.

\section{Cutaneous Leishmaniasis and Pregnancy}

Immunological alterations observed during pregnancy affect the course of parasitic infections, such as cutaneous and visceral leishmaniasis (Morgan et al., 2007; Verma et al., 2014; Berger et al., 2017). The worsening of ATL lesions during pregnancy is associated with changes in the innate and adaptive maternal immune response that normalizes postpartum (Conceição-Silva et al., 2013). Pregnant women can develop exuberant and atypical lesions (Guimarães et al., 2009; Conceição-Silva et al., 2013), as well as preterm births and stillbirths (Morgan et al., 2007). Pregnant woman showed an increase in Th2 cells and a reduction in type 1 responsiveness (Conceição-Silva et al., 2013) that is important for healing in leishmaniasis. Although T lymphocytes and macrophages are abundant and similar during pregnancy and postpartum, NOS2 in situ expression are more intense postpartum than during pregnancy (Conceição-Silva et al., 2013). The increase of NOS2 expression postpartum is accompanied by an increase of IFN- $\gamma$, whereas IL-10 does not show alterations in situ. Arginase activity increases during pregnancy and declines at the time of birth to levels like those observed in ATL nonpregnant controls. During pregnancy, a transient modulation of maternal immune responses was observed, characterized by the exacerbation of cutaneous lesions, increased parasite burdens, and reduction of IFN- $\gamma$ and NOS2, indicating a diminished Th1 response, which was restored postpartum and was associated with the resolution of the wound (Conceição-Silva et al., 2013).

Furthermore, Th1 response against L. major in pregnant C57BL/6 mice increased implantation failure and fetal resorptions and was correlated with increased IFN- $\gamma$ and TNF and reduced IL-10 production by placental cells (Krishnan et al., 1996). In a murine model of experimental infection with $L$. mexicana during pregnancy, resorption and fetal death were observed in a pregnant group (Avila-García et al., 2013). Parasite DNA was found in all placentas evaluated confirming that Leishmania is transmitted transplacentally and causes fetal damages in this murine model (Avila-García et al., 2013). These data, in part, could suggest and explain the low number of pregnant women infected with Leishmania parasites. Altogether, the data showed that immunomodulation of maternal immune responses during pregnancy has beneficial consequences for the fetus and its development, however, favors Leishmania parasite growth and lesion development reflecting in exuberant and atypical lesions.

\section{Cutaneous Leishmaniasis and Immunosuppression}

There are numerous causes of immunosuppression in human patients, for example HIV infection, cancer, immunosuppressive treatments and transplantation. The association between immunosuppression and atypical cutaneous manifestations of leishmaniasis was systematically reviewed in a previous study (Meireles et al., 2017) and described as case reports by several authors (Gontijo et al., 2002; Tuon et al., 2007, 2014; Mortazavi et al., 2014; Souza et al., 2017; among others). In a case of a kidney transplant patient infected with L. braziliensis, a concurrent cutaneous, visceral and ocular leishmaniasis was observed (Gontijo et al., 2002). Parasites were isolated from different tissues/sites, such as iliac crest, aqueous humor, and vitreous body suggesting that the immunosuppressive drugs favored the dissemination of Leishmania, to different organs including immune-privileged areas (Gontijo et al., 2002). Reactivation of mucosal and cutaneous leishmaniasis was also demonstrated in a renal transplanted patient (Tuon et al., 2014), as well as cutaneous leishmaniasis reactivation years after treatment caused by systemic corticosteroids (Tuon et al., 2007).

More recently, cases of patients with severe autoimmune diseases who had to be under therapy involving immunosuppressant drugs such as methotrexate (MTX), monoclonal antibodies (mAbs), mainly TNF-inhibitory mAbs, and prednisone, and who presented tegumentary and/or visceral lesions have been reported even in the absence of a prior compatible history. The association of anti-TNF therapy and the increased risk for developing opportunistic infections has also been associated (Neumayr et al., 2013; Calabrò et al., 2016). Regardless of the fact that most of the cases published showed a reactivation of visceral leishmaniasis, cases of association between rheumatoid arthritis (RA) and ATL were also described (Souza et al., 2017). Despite the increasing amount of information available, most physicians still have problems to rapidly diagnose cutaneous leishmaniasis (CL) or mucosal leishmaniasis (ML) in patients submitted to immunosuppressive treatment since these patients very often show epidemiological evidence of previous leishmaniasis, however, they live in non-endemic regions of neglected tropical diseases at the time of diagnosis.

The worsening of clinical manifestations, multiple lesions and high degree of relapses post-treatment in ATL patients coinfected with HIV were previously described (Rosatelli et al., 1998; Puig and Pradinaud, 2003; Lindoso et al., 2009, 2016; Giavedoni et al., 2015; Calvopina et al., 2017). In a study of fifteen cases of AIDS/TL, Lindoso et al. (2009) observed mucosal lesions progress in $80 \%$ of the patients, disseminated lesions in $60 \%$ and genital lesions in $27 \%$ of the patients. All of them were treated and $56 \%$ of the patients showed relapses. The immunological bases of increased immunosuppression of HIV/leishmaniasis coinfected patients have been studied. Leishmania infection can increase the degree of immune system activation in individuals concomitantly infected with HIV (Santos-Oliveira et al., 2010). Although the alterations were more intense for VL/HIV-AIDS patients than for TL/HIV-AIDS ones, the authors observed lower $\mathrm{CD}^{+} \mathrm{T}$ cell counts and higher proportion of activated $\mathrm{T}$ lymphocytes in co-infected patients even when HIV viral load was suppressed under HAART (Santos-Oliveira et al., 2010). In HIV-AIDS patients the decrease in the pool of $\mathrm{CD}^{+} \mathrm{T}$ cells and consequent diminution of the $\mathrm{CD} 4 / \mathrm{CD} 8$ ratio, produced by 
HIV infection provokes a generalized immune depression (DaCruz et al., 1992). In this study, the patient's disseminated clinical manifestation was probably related to the inability of the T cellmediated immune responses to control the spread of Leishmania infection (Da-Cruz et al., 1992). HIV/Leishmania co-infected patients also present a reduction in the lymphoproliferative response to Leishmania antigens associated with the decreased quantity of both effector memory and central memory CD4 ${ }^{+}$ T-cells (Góis et al., 2014). A reduction in the IFN- $\gamma$ and IL13 levels and the ratio of IFN- $\gamma /$ IL-10 produced in response to stimulation with soluble Leishmania antigens were also observed in individuals infected with HIV and/or cutaneous leishmaniasis (Rodrigues et al., 2011). They suggested that alterations in cytokines expression create a microenvironment that favors the replication and the spread of the Leishmania parasites, leading to the dissemination of cutaneous infection and the visceralization of typically dermotropic species (Rodrigues et al., 2011).

\section{PARASITE PERSISTENCE}

The reactivation of leishmaniasis lesions after clinical cure in immunosuppressed patients led to the discussion on parasitological cure and parasite persistence in leishmaniasis. How and why some parasites persist for long periods, perhaps the entire life of the infected individual? What would be the advantage and the disadvantage of this fact? Many answers have been obtained, but some questions have not been made clear yet.

The inflammatory process is a complex event that produces energy expenditure for its organization, and control, very important step because unbalanced inflammation can produce as much or more tissue damage as the stimulus, which originated it. Therefore, our organism uses several mechanisms to have efficient, precise and fast action. Thus, the inflammation necessary to control an infection may not be sufficient to produce the complete elimination of the infectious agent. In addition, the presence of the pathogen in a residual and controlled manner may even be beneficial in the sense of constantly and limitedly stimulating the immune system; consequently the organism would always be prepared for new infections. The problem is when this interaction parasite-host becomes unbalanced. At this time, the infection may reappear, either by an increase in the virulence of the parasite or by alteration of the immune response that controls the infection.

One of the first pieces of information about the residual presence of Leishmania parasites in tissue after the clinical healing was obtained in a murine model. Aebischer et al. (1993) obtained confirmation of the presence of $L$. major in viscera of C57BL/ 6 mice cured for more than 1 year. In addition, the authors were able to demonstrate the infectivity of the isolated parasites. Parasite persistence has been also demonstrated in clinical cured patients (Schubach et al., 1998; Coutinho et al., 2002; Mendonça et al., 2004; Oliveira-Camera et al., 2006; Morgado et al., 2010; Castro et al., 2017; Martínez-Valencia et al., 2017). Leishmania persists in skin and mucosal tissues in a high proportion of patients who achieved therapeutic cure of CL (Martínez-Valencia et al., 2017). The possibility of parasite persistence after clinical cure suggests that the immune response can control, but not fully eliminate the infection (Coutinho et al., 2002; Morgado et al., 2010; Conceição-Silva et al., 2010). In this context, healed leishmaniasis cutaneous lesions were evaluated after 1 and 3-year post-clinical cure (Morgado et al., 2010). Although the patients show the epithelization of lesions, microscopically the amastigotes persist in the skin, as well as the inflammatory reaction as focal or nested infiltration. The equilibrium between parasite and host is progressively achieved over the years with the reduction of inflammatory cells at the site of lesion (Morgado et al., 2010). Once achieved, this

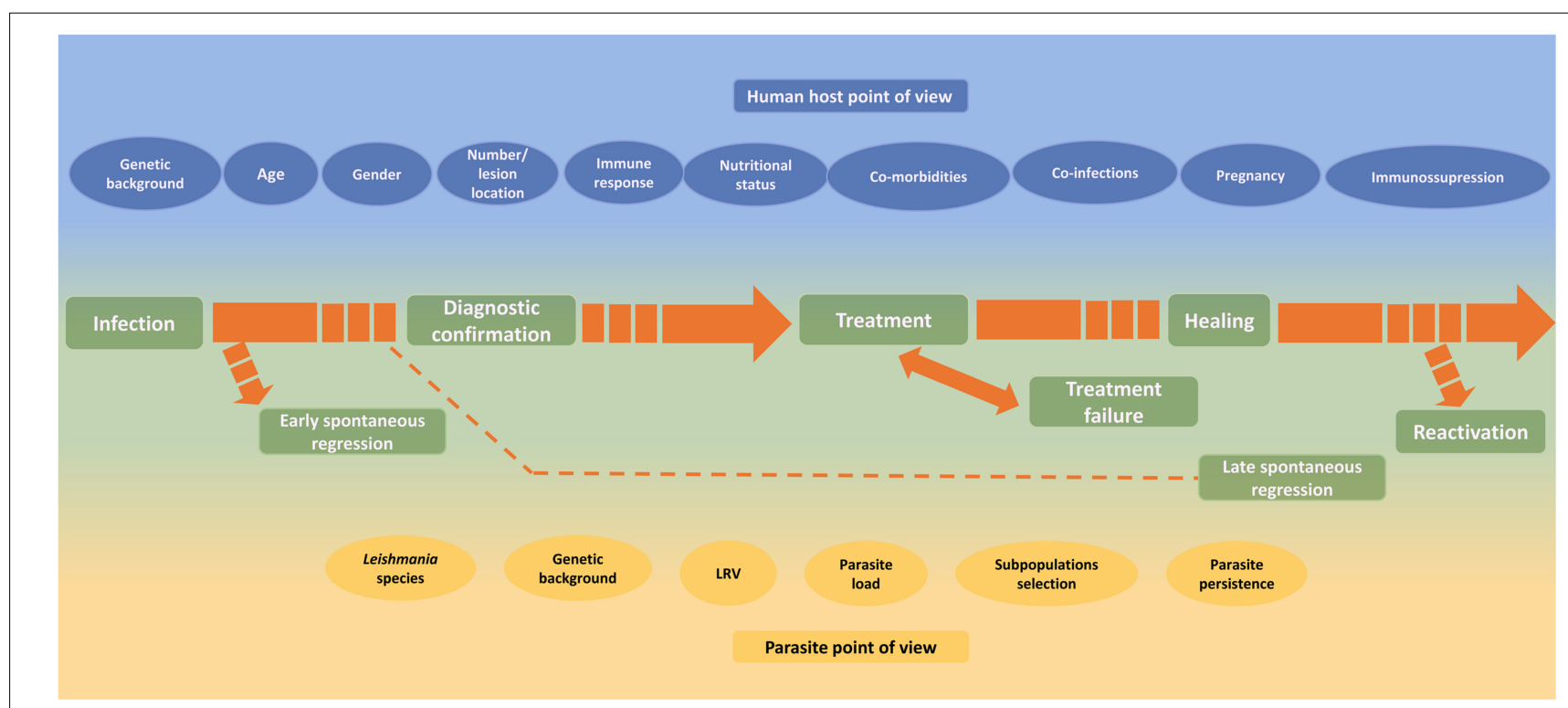

FIGURE 3 | Host and parasite factors that may influence the course of infection, the lesion healing and the reactivation of cutaneous leishmaniasis. 
equilibrium is maintained by the relation between $\mathrm{T}$ reg cells and effector lymphocytes (Mendez et al., 2004). Trauma, elderly patients, comorbidities, co-infections and immunosuppression can destabilize this equilibrium leading to reactivation of the lesion (Oliveira-Neto et al., 1998; Lages et al., 2008; AzeredoCoutinho et al., 2016; Souza et al., 2017; Martínez et al., 2018).

In the murine model experimentally infected with $L$. major, parasite persistence in the skin is mediated by $\mathrm{CD} 4^{+} \mathrm{CD} 25^{+}$Treg cell accumulation (Belkaid et al., 2002; Yurchenko et al., 2006). $\mathrm{CD} 4{ }^{+} \mathrm{CD} 25^{+}$nTreg cells migrate to $L$. major-infected dermal sites through the CCR5 signaling, promoting the establishment of infection and long-term survival of the parasite in the host (Mendez et al., 2004; Yurchenko et al., 2006). In the lesion site, $\mathrm{CD} 4{ }^{+} \mathrm{CD} 25^{+} \mathrm{T}$ cells suppress the ability of $\mathrm{CD} 4{ }^{+} \mathrm{CD} 25^{-}$ effector T cells to eliminate the parasite by both, IL-10-dependent and IL-10-independent mechanisms (Belkaid et al., 2002; Viana da Costa et al., 2002). The effector and regulatory $\mathrm{T}$ cells balance established in sites of chronic infection might reflect both parasite and host survival strategies since the sterilizing immunity achieved in mice with impaired IL-10 activity is followed by the loss of immunity to reinfection (Belkaid et al., 2001, 2002). Fibroblasts were identified as safe cell targets for the Leishmania parasites in clinically latent disease (Bogdan and Röllinghoff, 1998). When compared with macrophages, these cells showed a reduced ability to express type 2 nitric oxide synthase and to kill intracellular L. major (Bogdan and Röllinghoff, 1998). Stenger et al. (1996) showed the reactivation of latent leishmaniasis by inhibition of inducible nitric oxide synthase in mice experimentally infected with $L$. major. However, recently two populations: one rapidly replicating, like parasites in acute infections, and another showing little evidence of replication were demonstrated in the persistent infection by L. major (Mandell and Beverley, 2016, 2017). The persistent parasite were found residing in macrophages and DCs expressing inducible nitric oxide synthase (iNOS), instead of "safe" immunoprivileged cell types, suggesting that some populations of Leishmania may be resistant to NO (Mandell and Beverley, 2017). L. major-infected dendritic cells and macrophages in lymph nodes of immune animals representing long-term host cells were demonstrated a long time ago (Moll et al., 1995). Once dendritic cells could present endogenous parasite antigen to $\mathrm{T}$ cells, long-term infected dendritic cells may thus allow the sustained stimulation of a population of parasite-specific $\mathrm{T}$ cells, protecting the mice from reinfection favoring the maintenance of $\mathrm{T}$ cell memory (Moll et al., 1995).

There are various mechanisms of immune escape described for Leishmania, which led to parasite persistence in the host. They include: passive protection of the parasite against antileishmanial products and retreat into "safe target cells," active suppression

\section{REFERENCES}

Adaui, V., Lye, L. F., Akopyants, N. S., Zimic, M., Llanos-Cuentas, A., Garcia, L., et al. (2016). Association of the endobiont double-stranded RNA virus LRV1 with treatment failure for human Leishmaniasis Caused by Leishmania of the synthesis of reactive oxygen or nitrogen intermediates, modulation of the host cytokine response, inhibition of antigen-presentation and $\mathrm{T}$ cell-stimulation, and induction and expansion of counterprotective Th cells (Bogdan and Röllinghoff, 1998). Despite the fact that these mechanisms alone are not able to guarantee the survival of the parasite, together they might provide the safe environment protecting the parasite from elimination (Bogdan and Röllinghoff, 1998).

\section{CONCLUDING REMARKS}

Different factors such as Leishmania species, host genetic background, age, nutritional status, comorbidities, lesion duration, number and localization of lesions, drug metabolism, irregular treatment, individual host cellular immune response, among others were described as capable of influencing the TL outcome (Figure 3). Unfortunately, despite an impressive amount of information, a conclusive understanding about the magnitude of their roles remains under construction. In addition, a multifactorial influence cannot be discarded. A better knowledge of the role of different factors from either parasites or patient sites can improve the understanding of the influence of these factors in the healing process, clinical healing maintenance and reactivation of human tegumentary leishmaniasis. This knowledge is fundamental to better understand disease progression, thus allowing better treatment and control, and improvement in patient care.

\section{AUTHOR CONTRIBUTIONS}

FC-S, JL-S, and FM conceived the manuscript. FC-S and FM conceived the figures. FM prepared the figures. JL-S prepared the tables. FC-S, JL-S, and FM wrote, reviewed, and approved the manuscript.

\section{FUNDING}

This study was funding by PAEF-IOC-Fiocruz (IOC-008-FIO-15) and (IOC-008-FIO-15-63).

\section{ACKNOWLEDGMENTS}

We would like to thank Dr. M. R. Lyra and LaPClin Vigileish National Institute of Infectology Evandro Chagas -INI- Fiocruz by the photos in Figure 1 and Dr. M. I. F. Pimentel for a critical review of Table 1 .

braziliensis in Peru and Bolivia. J. Infect. Dis. 213, 112-121. doi: 10.1093/infdis/ jiv354

Aebischer, T., Moody, S. F., and Handman, E. (1993). Persistent of virulent Leishmania major in murine cutaneous Leishmaniasis: a possible hazard for the host. Infect. Immun. 61, 220-226. 
Aksoy, M., Doni, N., Ozkul, H. U., Yesilova, Y., Ardic, N., Yesilova, A., et al. (2016). Pediatric cutaneous Leishmaniasis in an endemic region in turkey: a retrospective analysis of 8786 cases during 1998-2014. PLoS Negl. Trop. Dis. 10:e0004835. doi: 10.1371/journal.pntd.0004835

Almeida, M. C., Vilhena, V., Barral, A., and Barral-Netto, M. (2003). Leishmanial infection: analysis of its first steps. A review. Mem. Inst. Oswaldo Cruz 98, 861-870. doi: 10.1590/S0074-02762003000700001

AlSamarai, A. M., and AlObaidi, H. S. (2009). Cutaneous Leishmaniasis in Iraq. J. Infect. Dev. Ctries 3, 123-129. doi: 10.3855/jidc.59

Alvar, J., Vélez, I. D., Bern, C., Herrero, M., Desjeux, P., Cano, J., et al. (2012). Control team. Leishmaniasis worldwide and global estimates of its incidence. PLoS One. 7:e35671. doi: 10.1371/journal.pone.0035671

Alves-Ferreira, E. V. C., Toledo, J. S., Oliveira, A. H. C., Ferreira, T. R., Ruy, P. C., Pinzan, C. F., et al. (2015). Differential gene expression and infection profiles of cutaneous and mucosal Leishmania braziliensis isolates from the same patient. PLoS Negl. Trop. Dis. 9:e0004018. doi: 10.1371/journal.pntd.0004018

Ameen, M. (2010). Cutaneous Leishmaniasis: advances in disease pathogenesis, diagnostics and therapeutics. Clin. Exp. Dermatol. 35, 699-705. doi: 10.1111/ j.1365-2230.2010.03851.x

Antonio, L. F., Fagundes, A., Oliveira, R. V., Pinto, P. G., Bedoya-Pacheco, S. J., Vasconcellos, E. C., et al. (2014). Montenegro skin test and age of skin lesion as predictors of treatment failure in cutaneous Leishmaniasis. Rev. Inst. Med. Trop. São Paulo 56, 375-380. doi: 10.1590/S0036-46652014000500002

Antonio, L. F., Lyra, M. R., Saheki, M. N., Schubach, A. O., Miranda, L. F. C., Madeira, M. F., et al. (2017). Effect of secondary infection on epithelialization and total healing of cutaneous Leishmaniasis lesions. Mem. Inst. Oswaldo Cruz 112, 640-646. doi: 10.1590/0074-02760160557

Avila-García, M., Mancilla-Ramírez, J., Segura-Cervantes, J., Farfan-Labonne, B., Ramírez-Ramírez, A., and Galindo-Sevilla, N. (2013). Transplacental transmission of cutaneous Leishmania mexicana strain in BALB/c Mice. Am. J. Trop. Med. Hyg. 89, 354-358. doi: 10.4269/ajtmh.12-0716

Awasthi, A., Mathur, R. K., and Saha, B. (2004). Immune response to Leishmania infection. Indian J. Med. Res. 119, 238-258.

Azeredo-Coutinho, R. B., and Mendonça, S. C. F. (2014). "Clinical forms of tegumentary Leishmaniasis in the Americas," in Leishmaniasis of the American Continent, 1 Edn, eds F. Conceição-Silva and C. R. Alves (Rio de Janeiro: Ed Fiocruz), 311-326.

Azeredo-Coutinho, R. B., Mendonça, S. C. F., Callahan, H., Portal, A. C., and Grogl, M. (2007). Sensitivity of Leishmania braziliensis promastigotes to meglumine antimoniate (Glucantime) is higher than that of other Leishmania species and correlated with response to therapy in American tegumentary Leishmaniasis. J. Parasitol. 93, 688-693. doi: 10.1645/GE-1031R.1

Azeredo-Coutinho, R. B., Pimentel, M. I., Zanini, G. M., Madeira, M. F., Cataldo, J. I., Schubach, A. O., et al. (2016). Intestinal helminth coinfection is associated with mucosal lesions and poor response to therapy in American tegumentary Leishmaniasis. Acta Trop. 154, 42-49. doi: 10.1016/j.actatropica.2015.10.015

Baccan, G. C., Oliveira, F., Sousa, A. D., Cerqueira, N. A., Costa, J. M. L., BarralNetto, M., et al. (2011). Hormone levels are associated with clinical markers and cytokine levels in human localized cutaneous Leishmaniasis". Brain Behav. Immun. 25, 548-554. doi: 10.1016/j.bbi.2010.12.009

Bacellar, O., Lessa, H., Schriefer, A., Machado, P., Ribeiro-de-Jesus, A., Dutra, W. O., et al. (2002). Up-regulation of Th1-type responses in mucosal Leishmaniasis patients. Infect. Immun. 70, 6734-6740. doi: 10.1128/IAI.70.12. 6734-6740.2002

Banerjee, A., Bhattacharya, P., Joshi, A. B., Ismail, N., Dey, R., and Nakhasi, H. L. (2016). Role of pro-inflammatory cytokine IL-17 in Leishmania pathogenesis and in protective immunity by Leishmania vaccines. Cell. Immun. 309, 37-41. doi: 10.1016/j.cellimm.2016.07.004

Baptista, C., Schubach, A. O., Madeira, M. F., Leal, C. A., Pires, M. Q., Oliveira, F. S., et al. (2009). Leishmania (Viannia) braziliensis genotypes identified in lesions of patients with atypical or typical manifestations of tegumentary Leishmaniasis: evaluation by two molecular markers. Exp. Parasitol. 121, 317-322. doi: 10. 1016/j.exppara.2008.12.006

Belkaid, Y., Hoffmann, K. F., Mendez, S., Kamhawi, S., Udey, M. C., Wynn, T. A., et al. (2001). The role of interleukin (IL)-10 in the persistence of Leishmania major in the skin after healing and the therapeutic potential of Anti-IL-10 receptor antibody for sterile cure. J. Exp. Med. 194, 1497-1506. doi: 10.1084/ jem.194.10.1497
Belkaid, Y., Mendez, S., Lira, R., Kadambi, N., Milon, G., and Sacks, D. (2000). A natural model of Leishmania major infection reveals a prolonged "silent" phase of parasite amplification in the skin before the onset of lesion formation and immunity. J. Immunol. 165, 969-977. doi: 10.4049/jimmunol.165. 2.969

Belkaid, Y., Von Stebut, E., Mendez, S., Lira, R., Caler, E., Bertholet, S., et al. (2002). CD8 + T cells are required for primary immunity in C57BL/6 mice following low-dose, intradermal challenge with Leishmania major. J. Immunol. 168, 3992-4000. doi: 10.4049/jimmunol.168.8.3992

Berger, B. A., Bartlett, A. H., Saravia, N. G., and Galindo Sevilla, N. (2017). Pathophysiology of Leishmania infection during pregnancy. Trends Parasitol. 33, 935-946. doi: 10.1016/j.pt.2017.08.012

Bilbao-Ramos, P., Dea-Ayuela, M. A., Cardenas-Alegría, O., Salamanca, E., Santalla-Vargas, J., Benito, C., et al. (2017). Leishmaniasis in the major endemic region of plurinational state of Bolivia: species identification, phylogeography and drug susceptibility implications. Acta Trop. 176, 150-161. doi: 10.1016/j. actatropica.2017.07.026

Bittar, R. C., Nogueira, R. S., Vieira-Gonçalves, R., Pinho-Ribeiro, V., Mattos, M. S., Oliveira-Neto, M. P., et al. (2007). T-cell responses associated with resistance to Leishmania infection in individuals from endemic areas for Leishmania (Viannia) braziliensis. Mem. Inst. Oswaldo Cruz 102, 625-630. doi: 10.1590/ S0074-02762007005000069

Bittencourt, A. L., Costa, J. M., Carvalho, E. M., and Barral, A. (1993). Leishmaniasis recidiva cutis in American cutaneous Leishmaniasis. Int. J. Dermatol. 32, 802-805. doi: 10.1111/j.1365-4362.1993.tb02767.x

Bogdan, C., and Röllinghoff, M. (1998). The immune response to Leishmania: mechanisms of parasite control and evasion. Int. J. Parasitol. 28, 121-134. doi: 10.1016/S0020-7519(97)00169-0

Bourreau, E., Gineuves, M., Prévot, G., Hartley, M. A., Gangneux, J. P., RobertoGangneux, F., et al. (2016). Presence of Leishmania RNA virus 1 in Leishmania guyanensis increases the risk of first-line treatment failure and symptomatic relapse. J. Infect. Dis. 213, 105-111. doi: 10.1093/infdis/jiv355

Brazil (2017). Ministry of Health- SVS. [Manual of Surveillance of Cutaneous Leishmaniasis] Brasília, Brazil, 2017. Available at: http://bvsms.saude.gov.br/ bvs/publicacoes/manual_vigilancia_leishmaniose_tegumentar.pdf

Bretscher, P. A., Wei, G., Menon, J. N., and Bielefeldt-Ohmann, H. (1992). Establishment of stable, cell-mediated immunity that makes "susceptible" mice resistant to Leishmania major. Science 257, 539-542. doi: 10.1126/science. 1636090

Buitrago, R., Cupolillo, E., Bastrenta, B., Le Pont, F., Martinez, E., Barnabé, C., et al. (2011). PCR-RFLP of ribosomal internal transcribed spacers highlights inter and intra-species variation among Leishmania strains native to la Paz, Bolivia. Infect. Genet. Evol. 11, 557-563. doi: 10.1016/j.meegid.2010.11.019

Calabrò, A., Caterino, A. L., Elefante, E., Valentini, V., Vitale, A., Talarico, R., et al. (2016). One year in review 2016: novelties in the treatment of rheumatoid arthritis. Clin. Exp. Rheumatol. 34, 357-372.

Calvopina, M., Aguirre, C. W., Castillo, A., Abbasi, I., and Warburg, A. (2017). Coinfection of Leishmania guyanensis and human immunodeficiency virusacquired immune deficiency syndrome: report of a case of disseminated cutaneous Leishmaniasis in Ecuador. Am. J. Trop. Med. Hyg. 96, 1151-1154. doi: 10.4269/ajtmh.16-0431

Camara-Coelho, L. I., Paes, M., Guerra, J. A., Barbosa, M. G., Coelho, C., Lima, B., et al. (2011). Characterization of Leishmania spp. causing cutaneous Leishmaniasis in Manaus, Amazonas, Brazil. Parasitol. Res. 108, 671-677. doi: 10.1007/s00436-010-2139-9

Campanelli, A. P., Roselino, A. M., Cavassani, K. A., Pereira, M. S., Mortara, R. A., Brodskyn, C. I., et al. (2006). CD4+CD25+ T cells in skin lesions of patients with cutaneous Leishmaniasis exhibit phenotypic and functional characteristics of natural regulatory T cells. J. Infect. Dis. 193, 1313-1322. doi: 10.1086/502980

Cantanhêde, L. M., Silva Júnior, C. F., Ito, M. M., Felipin, K. P., Nicolete, R., Salcedo, M. V., et al. (2015). Further evidence of an association between the presence of Leishmania RNA Virus 1 and the mucosal manifestations in tegumentary Leishmaniasis patients. PLoS Negl. Trop. Dis. 9:e0004079. doi: 10.1371/journal.pntd.0004079

Carvalho, A. M., Amorim, C. F., Barbosa, J. L., Lago, A. S., and Carvalho, E. M. (2015). Age modifies the immunologic response and clinical presentation of American tegumentary Leishmaniasis. Am. J. Trop. Med. Hyg. 92, 1173-1177. doi: 10.4269/ajtmh.14-0631 
Carvalho, L. M. V., Pimentel, M. I. F., Conceição-Silva, F., Vasconcellos, E. C. F., Valete-Rosalino, C. M., Lyra, M. R., et al. (2017). Sporotrichoid Leishmaniasis: a cross-sectional clinical, epidemiological and laboratory study in Rio de Janeiro State, Brazil. Rev. Inst. Med. Trop. São Paulo 59:e33. doi: 10.1590/S16789946201759033

Castro, M. D. M., Cossio, A., Velasco, C., and Osorio, L. (2017). Risk factors for therapeutic failure to meglumine antimoniate and miltefosine in adults and children with cutaneous Leishmaniasis in Colombia: a cohort study. PLoS Negl. Trop. Dis. 11:e0005515. doi: 10.1371/journal.pntd.0005515

Chambers, S. M., and Goodell, M. A. (2007). Hematopoietic stem cell aging: wrinkles in stem cell potential. Stem Cell Rev. 3, 201-211. doi: 10.1007/s12015007-0027-1

Chiheb, S., Oudrhiri, L., Zouhair, K., Soussi-Abdallaoui, M., Riyad, M., and Benchikhi, H. (2012). [Unusual clinical presentation of cutaneous Leishmaniasis in three diabetic patients]. Ann. Dermatol. Venereol. 139, 542-545. doi: 10.1016/j.annder.2012.05.013

Cillari, E., Milano, S., Dieli, M., Arcoleo, F., Perego, R., Leoni, F., et al. (1992). Thymopentin reduces the susceptibility of aged mice to cutaneous Leishmaniasis by modulating CD4 T-cell subsets. Immunology 76, 362-366.

Conceição, J., Davis, R., Carneiro, P. P., Giudice, A., Muniz, A. C., Wilson, M. E., et al. (2016). Characterization of neutrophil function in human cutaneous Leishmaniasis caused by Leishmania braziliensis. PloS Negl. Trop. Dis. 10:e0004715. doi: 10.1371/journal.pntd.0004715

Conceição-Silva, F., Morgado, F. N., Costa-Santos, M., Miranda-Nascimento, C., and Oliveira-Mendes, S. (2010). Leishmania braziliensis and in situ host immune response: dispute or partnership? Rev. Soc. Bras. Med. Trop. 43, 63-70.

Conceição-Silva, F., Morgado, F. N., Pimentel, M. I. F., Vasconcellos, E. C. F., Schubach, A., Valete-Rosalino, C. M., et al. (2013). Two women presenting worsening cutaneous ulcers during pregnancy: diagnosis, immune response, and follow-up. PLoS Negl. Trop. Dis. 12:e2472. doi: 10.1371/journal.pntd. 0002472

Convit, J., Pinardi, M. E., and Rondon, A. J. (1972). Diffuse cutaneous Leishmaniasis: a disease due to an immunological defect of the host. Trans. $R$. Soc. Trop. Med. Hyg. 66, 603-610. doi: 10.1016/0035-9203(72)90306-9

Costa, J. M. L., Netto, E. M., Vale, K. C., Osaki, N. K., Tada, M. S., and Marsden, P. D. (1987). Spontaneous healing of cutaneous Leishmania braziliensis ulcers. Trans. R. Soc. Trop. Med. Hyg. 81:606. doi: 10.1016/0035-9203(87)90424-X

Costa, R. S., Carvalho, L. P., Campos, T. M., Magalhães, A. S., Passos, S. T., Schriefer, A., et al. (2018). Early cutaneous Leishmaniasis patients infected with Leishmania braziliensis express increased inflammatory responses after antimony therapy. J. Infect. Dis. 217, 840-850. doi: 10.1093/infdis/jix627

Courret, N., Lang, T., Milon, G., and Antoine, J. C. (2003). Intradermal inoculations of low doses of Leishmania major and Leishmania amazonensis metacyclic promastigotes induce different immunoparasitic processes and status of protection in BALB/c mice. Int. J. Parasitol. 33, 1373-1383. doi: 10. 1016/S0020-7519(03)00179-6

Courtenay, O., Peters, N. C., Rogers, M. E., and Bern, C. (2017). Combining epidemiology with basic biology of sand flies, parasites, and hosts to inform Leishmaniasis transmission dynamics and control. PLoS Pathog. 13:e1006571. doi: 10.1371/journal.ppat.1006571

Coutinho, S. G., Pirmez, C., and Da-Cruz, A. M. (2002). Parasitological and immunological follow-up of American tegumentary Leishmaniasis patients. Trans. R. Soc. Trop. Med. Hyg. 96(Suppl. 1), S173-S178. doi: 10.1016/S00359203(02)90072-6

Crosby, E. J., Clark, M., Novais, F. O., Wherry, E. J., and Scott, P. (2015). Lymphocytic choriomeningitis virus expands a population of NKG2D+CD8+ $\mathrm{T}$ cells that exacerbates disease in mice coinfected with Leishmania major. J. Immunol. 195, 3301-3310. doi: 10.4049/jimmunol.1500855

Cruz, I., Millet, A., Carrillo, E., Chenik, M., Salotra, P., Verma, S., et al. (2013). An approach for interlaboratory comparison of conventional and real-time PCR assays for diagnosis of human Leishmaniasis. Exp. Parasitol. 134, 281-289. doi: 10.1016/j.exppara.2013.03.026

Cuervo-Escobar, S., Losada-Barragán, M., Umaña-Pérez, A., Porrozzi, R., SaboiaVahia, L., Miranda, L. H., et al. (2014). T-cell populations and cytokine expression are impaired in thymus and spleen of protein malnourished BALB/c mice infected with Leishmania infantum. PLoS One 9:e114584. doi: 10.1371/ journal.pone. 0114584
Cunha, M. A., Leão, A. C. Q., Soler, R. C., and Lindoso, J. A. (2015). Efficacy and Safety of liposomal amphotericin B for the treatment of mucosal Leishmaniasis from the new world: a retrospective study. Am. J. Trop. Med. Hyg. 93, 12141218. doi: 10.4269/ajtmh.15-0033

Da-Cruz, A. M., Machado, E. S., Menezes, J. A., Rutowitsch, M. S., and Coutinho, S. G. (1992). Cellular and humoral immune responses of a patient with American cutaneous Leishmaniasis and AIDS. Trans. R. Soc. Trop. Med. Hyg. 86, 511-512. doi: 10.1016/0035-9203(92)90089-U

Da-Cruz, A. M., Oliveira, M. P., De Luca, P. M., Mendonça, S. C., and Coutinho, S. G. (1996). Tumor necrosis factor-alpha in human American tegumentary Leishmaniasis. Mem. Inst. Oswaldo Cruz 91, 225-229. doi: 10.1590/S007402761996000200019

Eren, R. O., Reverte, M., Rossi, M., Hartley, M. A., Castiglioni, P., Prevel, F., et al. (2016). Mammalian innate immune response to a Leishmania-resident RNA virus increases macrophage survival to promote parasite persistence. Cell Host Microbe 20, 318-328. doi: 10.1016/j.chom.2016.08.001

Faria, D. R., Gollob, K. J., Barbosa, J. Jr., Schriefer, A., Machado, P. R., Lessa, H., et al. (2005). Decreased in situ expression of interleukin-10 receptor is correlated with the exacerbated inflammatory and cytotoxic responses observed in mucosal Leishmaniasis. Infect. Immun. 73, 7853-7859. doi: 10.1128/IAI.73. 12.7853-7859.2005

Faria, D. R., Souza, P. E. A., Durães, F. V., Carvalho, E. M., Gollob, K. J., Machado, P. R., et al. (2009). Recruitment of CD8 + T cells expressing granzyme A is associated with lesion progression in human cutaneous Leishmaniasis. Parasite Immunol. 31, 432-439. doi: 10.1111/j.1365-3024.2009.01125.x

Gaafar, A., Veress, B., Permin, H., Kharazmi, A., Theander, T. G., and el Hassan, A. M. (1999). Characterization of the local and systemic immune responses in patients with cutaneous Leishmaniasis due to Leishmania major. Clin. Immunol. 91, 314-320. doi: 10.1006/clim.1999.4705

García-Bustos, M. F., González-Prieto, G., Ramos, F., Mora, M. C., Hashiguchi, Y., Parodi, C., et al. (2016). Clinical and epidemiological features of Leishmaniasis in northwestern-Argentina through a retrospective analysis of recent cases. Acta Trop. 154, 125-132. doi: 10.1016/j.actatropica.2015.11.008

Giavedoni, P., Iranzo, P., Fuertes, I., Estrach, T., and Gibert, M. A. (2015). Cutaneous Leishmaniasis: 20 years' experience in a Spanish tertiary care hospital. Actas Dermosifiliogr. 106, 310-316. doi: 10.1016/j.ad.2014.12.003

Góis, L. L., Mehta, S., Schooley, R. T., Badaró, R., and Grassi, F. R. (2014). Decreased memory T-cell response and function in human immunodeficiency virus-infected patients with tegumentary Leishmaniasis. Mem. Inst. Oswaldo Cruz 109, 9-14. doi: 10.1590/0074-0276130174

Gollob, K. J., Antonelli, L. R. V., Faria, D. R., Keesen, T. S. L., and Dutra, W. O. (2008). Immunoregulatory mechanisms and CD4-CD8- (double negative) $\mathrm{T}$ cell subpopulations in human cutaneous Leishmaniasis: a balancing act between protection and pathology. Int. Immunopharmacol. 8, 1338-1343. doi: 10.1016/ j.intimp.2008.03.016

Gomes, R., and Oliveira, F. (2012). The imune response to sand fly salivar proteins and its influence on Leishmania immunity. Front. Immunol. 3:110. doi: 10.3389/ fimmu.2012.00110

Gomes-Silva, A., Bittar, R. C., Nogueira, R. S., Amato, V. S., Mattos, M. S., OliveiraNeto, M. P., et al. (2007). Can interferon-gamma and interleukin-10 balance be associated with severity of human Leishmania (Viannia) braziliensis infection? Clin. Exp. Immunol. 149, 440-444. doi: 10.1111/j.1365-2249.2007.03436.x

Gontijo, B., and Carvalho, M. L. R. (2003). Leishmaniose tegumentar americana. Rev. Soc. Bras. Med. Trop. 36, 71-80. doi: 10.1590/S0037-86822003000100011

Gontijo, C. M. F., Pacheco, R. S., Orefice, F., Lasmar, E., Silva, E. S., and Melo, M. N. (2002). Concurrent cutaneous, visceral and ocular Leishmaniasis caused by Leishmania (Viannia) braziliensis in a kidney transplant patient. Mem. Inst. Oswaldo Cruz 97, 751-753. doi: 10.1590/S0074-02762002000500029

Guimarães, L. H., Machado, P. R. L., Lago, E. L., Morgan, D. J., Schriefer, A., Bacellar, O., et al. (2009). Atypical manifestations of tegumentary Leishmaniasis in a transmission area of Leishmania braziliensis in the State of Bahia, Brazil. Trans. R. Soc. Trop. Med. Hyg. 103, 712-715. doi: 10.1016/j.trstmh.2009.04.019 Guimarães-Costa, A. B., DeSouza-Vieira, T. S., Paletta-Silva, R., FreitasMesquita, A. L., Meyer-Fernandes, J. R., and Saraiva, E. M. (2014). 3'nucleotidase/nuclease activity allows Leishmania parasites to escape killing by neutrophil extracellular traps. Infect. Immun. 82, 1732-1740. doi: 10.1128/IAI. 01232-13 
Guimarães-Costa, A. B., Nascimento, M. T., Fromen, T. G. S., Soares, R. P., Morgado, F. N., Conceição-Silva, F., et al. (2009). Leishmania amazonensis promastigotes induce and are killed by neutrophil extracellular traps. Proc. Natl. Acad. Sci. U.S.A 106, 6748-6753. doi: 10.1073/pnas.090022 6106

Handler, M. Z., Patel, P. A., Kapila, R., Al-Qubati, Y., and Schwartz, R. A. (2015). Cutaneous and mucocutaneous Leishmaniasis: clinical perspectives. J. Am. Acad. Dermatol. 73, 897-908. doi: 10.1016/j.jaad.2014.08.051

Hejazi, S. H., Hoseini, S., Javanmard, S. H., Zarkesh, S. H., and Khamesipour, A. (2012). Interleukin-10 and transforming growth factor- $\beta$ in early and late lesions of patients with Leishmania major induced cutaneous Leishmaniasis. Iran. J. Parasitol. 7, 53-60.

Hoseini, S. G., Javanmard, S. H., Hejazi, S. H., Rafiei, L., Zarkesh, S. H., Karbalaii, K., et al. (2014). Comparison of immune regulatory factors in acute and chronic lesions of cutaneous Leishmaniasis due to Leishmania major. J. Res. Med. Sci. 19(Suppl. 1), S36-S40.

Hosken, N. A., Shibuya, K., Heath, A. W., Murphy, K. M., and O'Garra, A. (1995). The effect of antigen dose on CD4+ T helper cell phenotype development in a $\mathrm{T}$ cell receptor- $\alpha \beta$-transgenic model. J. Exp. Med. 182, 1579-1585. doi: 10.1084/jem.182.5.1579

Ibrahim, M. K., Barnes, J. L., Anstead, G. A., Jimenez, F., Travi, B. L., Peniche, A. G., et al. (2013). The malnutrition-related increase in early visceralization of Leishmania donovani is associated with a reduced number of lymph node phagocytes and altered conduit system flow. PLoS Negl. Trop. Dis. 7:e2329. doi: 10.1371 /journal.pntd.0002329

John, B., and Hunter, C. A. (2008). Neutrophil soldiers or Trojan horses? Science 321, 917-918. doi: 10.1126/science.1162914

Kevric, I., Cappel, M. A., and Keeling, J. H. (2015). New world and old world Leishmania infections. A practical review. Dermatil. Clin. 33, 579-593. doi: 10.1016/j.det.2015.03.018

Khezzani, B., and Bouchemal, S. (2017). Demographic and spatio-temporal distribution of cutaneous Leishmaniasis in the Souf oasis (Eastern South of Algeria): results of 13 years. Acta Trop. 166, 74-80. doi: 10.1016/j.actatropica. 2016.11.012

Kima, P. E., and Soong, L. (2013). Interferon gamma in Leishmaniasis. Front. Immunol. 4:156. doi: 10.3389/fimmu.2013.00156

Koltas, I. S., Uzun, F. E. S., and Alabaz, D. (2016). A comparative analysis of different molecular targets using PCR for diagnosis of old world Leishmaniasis. Exp. Parasitol. 164, 43-48. doi: 10.1016/j.exppara.2016.02.007

Krishnan, L., Guilbert, L. J., Wegmann, T. G., Belosevic, M., and Mosmann, T. R. (1996). T helper 1 response against Leishmania major in pregnant C57BL/6 mice increases implantation failure and fetal resorptions. Correlation with increased IFN- $\gamma$ and TNF and reduced IL-10 production by placental cells. J. Immunol. 156, 653-662.

Lages, C. S., Suffia, I., Velilla, P. A., Huang, B., Warshaw, G., Hildeman, D. A., et al. (2008). Functional regulatory $\mathrm{T}$ cells accumulate in aged hosts and promote chronic infectious disease reactivation. J. Immunol. 181, 1835-1848. doi: 10. 4049/jimmunol.181.3.1835

Lakhal-Naouar, I., Slike, B. M., Aronson, N. E., and Marovich, M. A. (2015). The immunology of a healing response in cutaneous Leishmaniasis treated with localized heat or systemic antimonial therapy. PLoS Negl. Trop. Dis. 9:e0004178. doi: 10.1371/journal.pntd.0004178

Lang, P. O., Samaras, D., Samaras, N., Govind, S., and Aspinall, R. (2011). Influenza vaccination in the face of immune exhaustion: is herd immunity effective for protecting the elderly? Influenza Res. Treat. 2011:419216. doi: 10.1155/2011/ 419216

Layegh, P., Ghazvini, K., Moghiman, T., Hadian, F., Zabolinejad, N., and Pezeshkpour, F. (2015). Bacterial contamination in cutaneous Leishmaniasis: its effect on the lesions' healing course. Indian J. Dermatol. 60:211. doi: 10.4103/ 0019-5154.152560

Lestinova, T., Rohousova, I., Sima, M., de Oliveira, C. I., and Volf, P. (2017). Insights into the sand fly saliva: blood-feeding and imune interactions between sand flies, hosts, and Leishmania. PLoS Negl. Trop. Dis. 11:e0005600. doi: 10.1371/journal.pntd.0005600

Lindoso, J. A. L., Barbosa, R. N., Posada-Vergara, M. P., Duarte, M. I. S., Oyafuso, L. K., Amato, V. S., et al. (2009). Unusual manifestations of tegumentary Leishmaniasis in aids patients from the new world. Br. J. Dermatol. 160, 311-318. doi: $10.1111 / j .1365-2133.2008 .08908 . x$
Lindoso, J. A. L., Costa, J. M. L., Queiroz, I. T., and Goto, H. (2012). Review of the current treatments for Leishmaniasis. Res. Rep. Trop. Med. 3, 69-77.

Lindoso, J. A. L., Cunha, M. A., Queiroz, I. T., and Moreira, C. H. V. (2016). Leishmaniasis-HIV coinfection: current challenges. Res. Palliat. Care 8, $147-156$.

Losada-Barragán, M., Umaña-Pérez, A., Cuervo-Escobar, S., Berbert, L. R., Porrozzi, R., Morgado, F. N., et al. (2017). Protein malnutrition promotes dysregulation of molecules involved in T cell migration in the thymus of mice infected with Leishmania infantum. Sci. Rep. 7:45991. doi: 10.1038/srep 45991

Macedo, D. H., Menezes-Neto, A., Rugani, J. M., Rocha, A. C., Silva, S. O., Melo, M. N., et al. (2016). Low frequency of LRV1 in Leishmania braziliensis strains isolated from typical and atypical lesions in the state of Minas Gerais, Brazil. Mol. Biochem. Parasitol. 210, 50-54. doi: 10.1016/j.molbiopara.2016.08.005

Machado, P., Araujo, C., Silva, A. T., Almeida, R. P., D’Oliveira, A. Jr., Bittencourt, A., et al. (2002). Failure of early treatment of cutaneous Leishmaniasis in preventing the development of an ulcer. Clin. Infect. Dis. 34, 69-73. doi: $10.1086 / 340526$

Machado, P. R., Rosa, M. E. A., Costa, D., Mignac, M., Silva, J. S., Schriefer, A., et al. (2011). Reappraisal of the immunopathogenesis of disseminated Leishmaniasis: in situ and systemic immune response. Trans. R. Soc. Trop. Med. Hyg. 105, 438-444. doi: 10.1016/j.trstmh.2011.05.002

Machado-Coelho, G. L. L., Caiaffa, W. T., Genaro, O., Magalhães, P. A., and Mayrink, W. (2005). Risk factors for mucosal manifestation of American cutaneous Leishmaniasis". Trans. R. Soc. Trop. Med. Hyg. 99, 55-61. doi: 10. 1016/j.trstmh.2003.08.001

Makala, L. H., Baban, B., Lemos, H., El-Awady, A. R., Chandler, P. R., Hou, D. Y., et al. (2011). Leishmania major attenuates host immunity by stimulating local indoleamine 2,3-dioxygenase expression. J. Infect. Dis. 203, 715-725. doi: 10.1093/infdis/jiq095

Mandell, M. A., and Beverley, S. M. (2016). Concomitant immunity induced by persistent Leishmania major does not preclude secondary re-infection: implications for genetic exchange, diversity and vaccination. PloS Negl. Trop. Dis. 10:e004811. doi: 10.1371/journal.pntd.0004811

Mandell, M. A., and Beverley, S. M. (2017). Continual renewal and replication of persistent Leishmania major parasites in concomitantly immune hosts. Proc. Nat. Acad. Sci. U.S.A. 114, E801-E810. doi: 10.1073/pnas.1619265114

Marlow, M. A., Boité, M. C., Ferreira, G. E. M., Steindel, M., and Cupolillo, E. (2014). Multilocus sequence analysis for Leishmania braziliensis outbreak investigation. PLoS Negl. Trop. Dis. 8:e2695. doi: 10.1371/journal.pntd.0002695

Martínez, D. Y., Verdonck, K., Kaye, P. M., Adaui, V., Polman, K., LlanosCuentas, A., et al. (2018). Tegumentary Leishmaniasis and coinfections other than HIV. PLoS Negl. Trop. Dis. 12:e0006125. doi: 10.1371/journal.pntd. 0006125

Martínez-Valencia, A. J., Daza-Rivera, C. F., Rosales-Chilama, M., Cossio, A., Rincón, E. J. C., Desai, M. M., et al. (2017). Clinical and parasitological factors in parasite persistence after treatment and clinical cure of cutaneous Leishmaniasis". PLoS Negl. Trop. Dis. 11:e0005713. doi: 10.1371/journal.pntd. 0005713

Marzochi, M. C. A., and Marzochi, K. B. F. (1994). Tegumentary and visceral leishmaniases in Brazil: emerging anthropozoonosis and possibilities for their control. Cad. Saude Publica 10, 359-375. doi: 10.1590/S0102311X1994000800014

Maspi, N., Abdoli, A., and Ghaffarifar, F. (2016). Pro- and anti-inflammatory cytokines in cutaneous Leishmaniasis: a review. Pathog. Glob. Health 110, 247-260. doi: 10.1080/20477724.2016.1232042

Meireles, C. B., Maia, L. C., Soares, G. C., Teodoro, I. P. P. T., Gadelha, M. S. V., Silva, C. G. L., et al. (2017). Atypical presentations of cutaneous Leishmaniasis: a systematic review. Acta Trop. 172, 240-254. doi: 10.1016/j.actatropica.2017. 05.022

Mendez, S., Reckling, S. K., Piccirillo, C. A., Sacks, D., and Belkaid, Y. (2004). Role for $\mathrm{CD} 4(+) \mathrm{CD} 25(+)$ regulatory $\mathrm{T}$ cells in reactivation of persistent Leishmaniasis and control of concomitant immunity. J. Exp. Med. 200, 201-210. doi: 10.1084/jem.20040298

Mendonça, M. G., Brito, M. E. F., Rodrigues, E. H. G., Bandeira, V., Jardim, M. L., and Abath, F. G. C. (2004). Persistence of Leishmania parasites in scars after clinical cure of American cutaneous Leishmaniasis: is there a sterile cure? J. Infect. Dis. 189, 1018-1023. doi: 10.1086/382135 
Menon, J. N., and Bretscher, P. A. (1996). Characterization of the immunological memory state generated in mice susceptible to Leishmania major following exposure to low doses of $L$. major and resulting in resistance to a normally pathogenic challenge. Eur. J. Immunol. 26, 243-249. doi: 10.1002/eji. 1830260138

Moll, H., Flohé, S., and Röllinghoff, M. (1995). Dendritic cells in Leishmania majorimmune mice harbor persistent parasites and mediate an antigen-specific $\mathrm{T}$ cell immune response. Eur. J. Immunol. 25, 693-699. doi: 10.1002/eji.18302 50310

Morgado, F. N., Cavalcanti, A. D., Miranda, L. H., O’Dwyer, L. H., Silva, M. R., Menezes, R. C., et al. (2016). Hepatozoon canis and Leishmania spp. coinfection in dogs diagnosed with visceral Leishmaniasis. Rev. Bras. Parasitol. Vet. 25, 450-458. doi: 10.1590/S1984-29612016065

Morgado, F. N., Nascimento, M. T. C., Saraiva, E. M., Oliveira-Ribeiro, C., Madeira, M. F., Costa-Santos, M., et al. (2015). Are neutrophil extracellular traps playing a role in the parasite control in active American tegumentary Leishmaniasis lesions? PLoS One 10:e0133063. doi: 10.1371/journal.pone.0133063

Morgado, F. N., Schubach, A., Valete-Rosalino, C. M., Quintella, L. P., Santos, G., Salgueiro, M. M., et al. (2008). Is the in situ inflammatory reaction an important tool to understand the cellular immune response in American tegumentary Leishmaniasis? Br. J. Dermatol. 158, 50-58. doi: 10.1111/j.1365-2133.2007. 08255.x

Morgado, F. N., Schubach, A., Vasconcellos, E. C. F., Azeredo-Coutinho, R. B., Valete-Rosalino, C. M., Quintella, L. P., et al. (2010). Signs of an in situ inflammatory reaction in scars of human American tegumentary Leishmaniasis. Parasite Immunol. 32, 285-295. doi: 10.1111/j.1365-3024.2009.01188.x

Morgan, D. J., Guimaraes, L. H., Machado, P. R. L., D’Oliveira, A., Almeida, R. P., Lago, E. L., et al. (2007). Cutaneous Leishmaniasis during pregnancy: exuberant lesions and potential fetal complications. Clin. Infect. Dis. 45, 478482. doi: $10.1086 / 520017$

Mortazavi, H., Salehi, M., and Kamyab, K. (2014). Reactivation of cutaneous Leishmaniasis after renal transplantation: a case report. Case Rep. Dermatol. Med. 2014:251423. doi: 10.1155/2014/251423

Mosimann, V., Neumayr, A., Paris, D. H., and Blum, J. (2018). Liposomal amphotericin B treatment of old world cutaneous and mucosal Leishmaniasis: a literature review. Acta Trop. 182, 246-250. doi: 10.1016/j.actatropica.2018. 03.016

Neumayr, A. L., Morizot, G., Visser, L. G., Lockwood, D. N., Beck, B. R., Schneider, S., et al. (2013). Clinical aspects and management of cutaneous Leishmaniasis in rheumatoid patients treated with TNF- $\alpha$ antagonists. Travel Med. Infect. Dis. 11, 412-420. doi: 10.1016/j.tmaid.2013

Newlove, T., Guimarães, L. H., Morgan, D. J., Alcântara, L., Glesby, M. J., Carvalho, E. M., et al. (2011). Antihelminthic therapy and antimony in cutaneous Leishmaniasis: a randomized, double-blind, placebo-controlled trial in patients co-infected with helminths and Leishmania braziliensis. Am. J. Trop. Med. Hyg. 84, 551-555. doi: 10.4269/ajtmh.2011.10-0423

Novais, F. O., and Scott, P. (2015). CD8+ T cells in cutaneous Leishmaniasis: the good, the bad and the ugly. Semin. Immunopathol. 37, 251-259. doi: 10.1007/ s00281-015-0475-7

Novais, F. O., Wong, A. C., Villareal, D. O., Beiting, D. P., and Scott, P. (2018). CD8 + T cell lack local signals to produce IFN- $\gamma$ in the skin during Leishmania infection. J. Immunol. 200, 1737-1745. doi: 10.4049/jimmunol.1701597

Nylén, S., and Eidsmo, L. (2012). Tissue damage and immunity in cutaneous Leishmaniasis. Parasite Immunol. 34, 551-561. doi: 10.1111/pim.12007

Oliveira, A. G. L., Brito, P. D., Schubach, A. O., Oliveira, R. V. C., Saheki, M. N., Lyra, M. R., et al. (2013). Influence of the nutritional status in the clinical and therapeutical evolution in adults and elderly with American tegumentary Leishmaniasis. Acta Trop. 128, 36-40. doi: 10.1016/j.actatropica.2013.06.005

Oliveira, L. F., Schubach, A. O., Martins, M. M., Passos, S. L., Oliveira, R. V., Marzochi, M. C., et al. (2011). Systematic review of the adverse effects of cutaneous Leishmaniasis treatment in the new world. Acta Trop. 118, 87-96. doi: 10.1016/j.actatropica.2011.02.007

Oliveira, W. N., Ribeiro, L. E., Schrieffer, A., Machado, M., Carvalho, E. M., and Bacellar, O. (2014). The role of inflammatory and anti-inflammatory cytokines in the pathogenesis of human tegumentar Leishmaniasis. Cytokine 66, 127-132. doi: 10.1016/j.cyto.2013.12.016

Oliveira-Camera, P., Junger, J., Pires, F. E. S. S., Mattos, M., Oliveira-Neto, M. P., Fernandes, O., et al. (2006). Haematogenous dissemination of Leishmania
(Viannia) braziliensis in human American tegumentary Leishmaniasis. Trans. R. Soc. Trop. Med. Hyg. 100, 1112-1117. doi: 10.1016/j.trstmh.2006.02.014

Oliveira-Neto, M. P., Mattos, M., Souza, C. S., Fernandes, O., and Pirmez, C. (1998). Leishmaniasis recidiva cutis in new world cutaneous Leishmaniasis". Int. J. Dermatol. 37, 846-849. doi: 10.1046/j.1365-4362.1998.00478.x

Oliveira-Neto, M. P., Schubach, A., Araujo, M. L., and Pirmez, C. (1996). High and low doses of antimony (Sbv) in American cutaneous Leishmaniasis. A five years follow-up study of 15 patients. Mem. Inst. Oswaldo Cruz 91, 207-209. doi: 10.1590/S0074-02761996000200016

Oliveira-Ribeiro, C., Pimentel, M. I. F., Oliveira, R. V. C., Fagundes, A., Madeira, M. F., Mello, C. X., et al. (2017). Clinical and laboratory profiles of patients with early spontaneous healing in cutaneous localized Leishmaniasis: a historical cohort study. BMC Infect. Dis. 17:559. doi: 10.1186/s12879-017-2658-4

O’Neal, S. E., Guimarães, L. H., Machado, P. R., Alcântara, L., Morgan, D. J., Passos, S., et al. (2007). Influence of helminth infections on the clinical course of and immune response to Leishmania braziliensis cutaneous Leishmaniasis. J. Infect. Dis. 195, 142-148. doi: 10.1086/509808

Osorio, Y., Bonilla, D. L., Peniche, A. G., Melby, P. C., and Travi, B. L. (2008). Pregnancy enhances the innate immune response in experimental cutaneous Leishmaniasis through hormone-modulated nitric oxide production. J. Leuk. Biol. 83, 1413-1422. doi: 10.1189/jlb.0207130

PAHO (2013). Organización Pan-Americana de la Salud Leishmaniasis en las Américas: Recomendaciones para el Tratamiento. Washington DC: PAHO, 6-15.

Palmeiro, M. R., Morgado, F. N., Valete-Rosalino, C. M., Martins, A. C., Moreira, J., Quintella, L. P., et al. (2012). Comparative study of the in situ immune response in oral and nasal mucosal Leishmaniasis. Parasite Immunol. 34, 23-31. doi: 10.1111/j.1365-3024.2011.01343.x

Parmentier, L., Cusini, A., Müller, N., Zangger, H., Hartley, M.-A., Desponds, C., et al. (2016). Severe cutaneous Leishmaniasis in a human immunodeficiency virus patient coinfected with Leishmania braziliensis and its endosymbiotic virus. Am. J. Trop. Med. Hyg. 94, 840-843. doi: 10.4269/ajtmh.15-0803

Pereira, L. O. R., Maretti-Mira, A. C., Rodrigues, K. M., Lima, R. B., Oliveira-Neto, M. P., Cupolillo, E., et al. (2013). Severity of tegumentary Leishmaniasis is not exclusively associated with Leishmania RNA virus 1 infection in Brazil. Mem. Inst. Oswaldo Cruz 108, 665-667. doi: 10.1590/0074-0276108052013021

Pereira, L. O. R., Moreira, R. B., Oliveira, M. P., Reis, S. O., Oliveira Neto, M. C., and Pirmez, C. (2017). Is Leishmania (Viannia) braziliensis parasite load associated with disease pathogenesis? Int. J. Infect. Dis. 57, 132-137. doi: 10.1016/j.ijid. 2017.01.036

Pereira-Carvalho, R., Mendes-Aguiar, C., Oliveira-Neto, M. P., Covas, C. J. F., Bertho, A. L., Da-Cruz, A. M., et al. (2013). Leishmania braziliensis-reactive T cells are down-regulated in long-term cured cutaneous Leishmaniasis, but the renewal capacity of T effector memory compartments is preserved. PLoS One 8:e81529. doi: 10.1371/journal.pone.0081529

Pérez, H., Malavé, I., and Arredondo, B. (1979). The effects of protein malnutrition on the course of Leishmania mexicana infection in C57BL/6 mice: nutrition and susceptibility to Leishmaniasis". Clin. Exp. Immunol. 38, 453-460.

Pfister, G., Weiskopf, D., Lazuard, D., Kovaiou, R. D., Cioca, D. P., Keller, M., et al. (2006). Naive T cells in the elderly: are they still there? Ann. N. Y. Acad. Sci. 1067, 152-157. doi: 10.1196/annals.1354.018

Ponte-Sucre, A., Gamarro, F., Dujardin, J. C., Barrett, M. P., López-Vélez, R., García-Hernández, R., et al. (2017). Drug resistance and treatment failure in Leishmaniasis: a 21st century challenge. PLoS Negl. Trop. Dis. 11:e0006052. doi: 10.1371/journal.pntd.0006052

Puig, L., and Pradinaud, R. (2003). Leishmania and HIV co-infection: dermatological manifestations. Ann. Trop. Med. Parasitol. 97(Suppl. 1), 107114. doi: $10.1179 / 000349803225002589$

Quintella, L. P., Passos, S. R., Miranda, L. H., Cuzzi, T., Barros, M. B., Francesconido-Vale, A. C., et al. (2012). Proposal of a histopathological predictive rule for the differential diagnosis between American tegumentary Leishmaniasis and sporotrichosis skin lesions. Br. J. Dermatol. 167, 837-846. doi: 10.1111/j.13652133.2012.11012.x

Rath, M., Muller, I., Kropf, P., Closs, E. I., and Munder, M. (2014). Metabolism via arginase or nitric oxide synthase: two competing arginine pathways in macrophages. Front. Immunol. 5:532. doi: 10.3389/fimmu.2014.00532

Reis, J. G. C., Mota-Reis, C. S., Costa, D. C. S., Lucena, M. M., Schubach, A., Oliveira, R. V. C., et al. (2016). Factors associated with clinical and 
topographical features of laryngeal tuberculosis. PLoS One 11:e0153450. doi: 10.1371/journal.pone. 0153450

Ribeiro-de-Jesus, A., Almeida, R. P., Lessa, H., Bacellar, O., and Carvalho, E. M. (1998). Cytokine profile and pathology in human Leishmaniasis. Braz. J. Med. Biol. Res. 31, 143-148. doi: 10.1590/S0100-879X1998000100020

Ribeiro-Romão, R. P., Moreira, O. C., Osorio, E. Y., Cysne-Finkelstein, L., GomesSilva, A., Valverde, J. G., et al. (2014). Comparative evaluation of lesion development, tissue damage, and cytokine expression in golden hamsters (Mesocricetus auratus) infected by inocula with different Leishmania (Viannia) braziliensis concentrations. Infect. Immun. 82, 5203-5213. doi: 10.1128/IAI. 02083-14

Rodrigues, A. M., Hueb, M., Santos, T., and Fontes, C. J. F. (2006). Fatores ligados ao insucesso do tratamento da leishmaniose cutânea com antimoniato de meglumina. Rev. Soc. Bras. Med. Trop. 39, 139-145. doi: 10.1590/S003786822006000200001

Rodrigues, M. Z. A., Grassi, M. F. R., Mehta, S., Zhang, X.-Q., Gois, L. L., Schooley, R. T., et al. (2011). Th1/Th2 cytokine profile in patients coinfected with HIV and Leishmania in Brazil. Clin. Vaccine Immunol. 18, 1765-1769. doi: 10.1128/ CVI.00076-11

Rojas, R., Valderama, L., Valderama, M., Varona, M. X., Ouellette, M., and Saravia, N. G. (2006). Resistance to antimony and treatment failure in human Leishmania (Viannia) infection. J. Infect. Dis. 193, 1375-1383. doi: 10.1086/ 503371

Rosatelli, J. B., Souza, C. S., Soares, F. A., Foss, N. T., and Roselino, A. M. (1998). Generalized cutaneous Leishmaniasis in acquired immunodeficiency syndrome. J. Eur. Acad. Dermatol. Venereol. 10, 229-232. doi: 10.1111/j.14683083.1998.tb00741.x

Rossi, M., and Fasel, N. (2018). How to master the host immune system? Leishmania parasites have the solutions! Int. Immunol. 30, 103-111. doi: 10. 1093/intimm/dxx075

Rubiano, L. C., Miranda, M. C., Arenas, S. M., Montero, L. M., RodríguezBarraquer, I., Garcerant, D., et al. (2012). Noninferiority of miltefosine versus meglumine antimoniate for cutaneous Leishmaniasis in Children. J. Infect. Dis. 205, 684-692. doi: 10.1093/infdis/jir816

Sadeghian, G., Ziaei, H., Bidabadi, S., and Baghbaderani, Z. (2011). Decreased effect of glucantime in cutaneous Leishmaniasis complicated with secondary bacterial infection. Indian J. Dermatol. 56, 37-39. doi: 10.4103/0019-5154.77549

Salgado, V. R., Queiroz, A. T. L., Sanabani, S. S., Oliveira, C. I., Carvalho, E. M., Costa, J. M. L., et al. (2016). The microbiological signature of human cutaneous Leishmaniasis lesions exhibits restricted bacterial diversity compared to healthy skin. Mem. Inst. Oswaldo Cruz 111, 241-251. doi: 10.1590/0074-02760150436

Santos, C. S., Boaventura, V., Cardoso, C. R., Tavares, N., Lordelo, M. J., Noronha, A., et al. (2013). CD8+ granzyme B+-mediated tissue injuri vs. $\mathrm{CD} 4+\mathrm{INF} \gamma+-$-mediated parasite killing in human cutaneous Leishmaniasis. J. Investig. Dermatol. 133, 1533-1540. doi: 10.1038/jid.2013.4

Santos, M. A., Marques, R. C., Farias, C. A., Vasconcelos, D. M., Stewart, J. M., Costa, D. L., et al. (2002). Predictors of an unsatisfactory response to pentavalent antimony in the treatment of American visceral Leishmaniasis. Rev. Soc. Bras. Med. Trop. 35, 629-633. doi: 10.1590/S0037-86822002000600014

Santos-Oliveira, J. R., Giacoia-Gripp, C. B. W., Oliveira, P. A., Amato, V. S., Lindoso, J. A. L., Goto, H., et al. (2010). High levels of T lymphocyte activation in Leishmania-HIV-1 co-infected individuals despite low HIV viral load. BMC Infect. Dis. 10:358. doi: 10.1186/1471-2334-10-358

Saravia, N. G., Segura, I., Holguin, A. F., Santrich, C., Valderrama, L., and Ocampo, C. (1998). Epidemiologic, genetic, and clinical associations among phenotypically distinct populations of Leishmania (Viannia) in Colombia. Am. J. Trop. Med. Hyg. 59, 86-94. doi: 10.4269/ajtmh.1998.59.86

Saravia, N. G., Weigle, K., Segura, I., Giannini, S. H., Pacheco, R., Labrada, L. A., et al. (1990). Recurrent lesions in human Leishmania braziliensis infectionreactivation or reinfection? Lancet 336, 398-402.

Satoskar, A., Al-Quassi, H. H., and Alexander, J. (1998). Sex-determined resistance against Leishmania mexicana is associated with the preferential induction of a Th1-like response and IFN-gamma production by female but not male DBA/2 mice. Immunol. Cell Biol. 76, 159-166. doi: 10.1046/j.1440-1711.1998. 00730.x

Schriefer, A., Schriefer, A. L. F., Góes-Neto, A., Guimarães, L. H., Carvalho, L. P., Almeida, R. P., et al. (2004). Multiclonal Leishmania braziliensis population structure and its clinical implication in a region of endemicity for American tegumentary Leishmaniasis. Infect. Immun. 72, 508-514. doi: 10.1128/IAI.72.1. 508-514.2004

Schubach, A., and Conceição-Silva, F. (2014). "State of the art in the treatment of American cutaneous Leishmaniasis in Brazil," in Leishmaniasis of the American Continent, 1 Edn, eds F. Conceição-Silva and C. R. ALVES (Rio de Janeiro: Ed Fiocruz), 391-412.

Schubach, A., Marzochi, M. C., Cuzzi-Maya, T., Oliveira, A. V., Araujo, M. L., Oliveira, A. L., et al. (1998). Cutaneous scars in American tegumentary Leishmaniasis patients: a site of Leishmania (Viannia) braziliensis persistence and viability eleven years after antimonial therapy and clinical cure. Am. J. Trop. Med. Hyg. 58, 824-827. doi: 10.4269/ajtmh.1998.58.824

Schubach, A. O., Marzochi, K. B., Moreira, J. S., Schubach, T. M., Araújo, M. L., Vale, A. C., et al. (2005). Retrospective study of 151 patients with cutaneous Leishmaniasis treated with meglumine antimoniate. Rev. Soc. Bras. Med. Trop. 38, 213-217. doi: 10.1590/S0037-86822005000300001

Scott, P., and Novais, F. O. (2016). Cutaneous Leishmaniasis: immune responses in protection and pathogenesis. Nat. Rev. Immunol. 16, 581-592. doi: 10.1038/nri. 2016.72

Silveira, F. T., Lainson, R., and Corbett, C. E. (2004). Clinical and immunopathological spectrum of American cutaneous Leishmaniasis with special reference to the disease in Amazonian Brazil: a review. Mem. Inst. Oswaldo Cruz 99, 239-251. doi: 10.1590/S0074-02762004000300001

Soong, L., Henard, C. A., and Melby, P. C. (2012). Immunopathogenesis of non-healing American cutaneous Leishmaniasis and progressive visceral Leishmaniasis. Semin. Immunopathol. 34, 735-751. doi: 10.1007/s00281-012$0350-8$

Souza, M. A., Castro, M. C., Oliveira, A. P., Almeida, A. F., Reis, L. C., Silva, C. J., et al. (2012). American tegumentary Leishmaniasis: cytokines and nitric oxide in active disease and after clinical cure, with or without chemotherapy. Scand. J. Immunol. 76, 175-180. doi: 10.1111/j.1365-3083.2012.02717.x

Souza, R. M., Andrade Junior, H. F., Duarte, M. I. S., Braz, L. M. A., Schubach, A., Conceição Silva, F., et al. (2017). Reactivation of cutaneous and mucocutaneous tegumentary Leishmaniasis in rheumatoid arthritis patients: an emerging problem? Rev. Inst. Med. Trop. São Paulo 59:e6. doi: 10.1590/S16789946201759006

Stenger, S., Donhauser, N., Thüring, H., Röllinghoff, M., and Bogdan, C. (1996). Reactivation of latent Leishmaniasis by inhibition of inducible nitric oxide synthase. J. Exp. Med. 183, 1501-1514. doi: 10.1084/jem.183.4.1501

Tacchini-Cottier, F., Zweifel, C., Belkaid, Y., Mukankundiye, C., Vasei, M., Launois, P., et al. (2000). An immunomodulatory function for neutrophils during the induction of a CD4+ Th2 response in BALB/c mice infected with Leishmania major. J. Immunol. 165, 2628-2636. doi: 10.4049/jimmunol.165.5. 2628

Tirera, S., Ginouves, M., Donato, D., Caballero, I. S., Bouchier, C., Lavergne, A., et al. (2017). Unraveling the genetic diversity and phylogeny of Leishmania RNA Virus 1 Strains of Infected Leishmania isolates circulating in French Guiana. PLoS Negl. Trop. Dis. 11:e0005764. doi: 10.1371/journal.pntd.000 5764

Travi, B. L., Osorio, Y., Melby, P. C., Chandrasekar, B., Arteaga, L., and Saravia, N. G. (2002). Gender is a major determinant of the clinical evolution and immune response in hamsters infected with Leishmania spp. Infect. Immun. 70, 2288-2296. doi: 10.1128/IAI.70.5.2288-2296.2002

Tuon, F. F., Amato, V. S., Floeter-Winter, L. M., Zampieri, R. A., Amato Neto, V., França, F. O. S., et al. (2007). Cutaneous Leishmaniasis reactivation 2 years after treatment caused by systemic corticosteroids - first report. Int. J. Dermatol. 46, 628-630. doi: 10.1111/j.1365-4632.2006.03096.x

Tuon, F. F., Amato, V. S., Graf, M. E., Siqueira, A. M., Nicodemo, A. C., and Neto, V. A. (2008). Treatment of new world cutaneous Leishmaniasis-a systematic review with a meta-analysis. Int. J. Dermatol. 47, 109-112. doi: 10.1111/j.13654632.2008.03417.x

Tuon, F. F., Bombonatto, G. M., Battaglin, E. R., Sakumoto, M. H., Amato, V. S., Camargo, R. A., et al. (2014). Reactivation of mucosal and cutaneous Leishmaniasis in a renal transplanted patient. Am. J. Trop. Med. Hyg. 91, 81-83. doi: 10.4269/ajtmh.13-0578

Unger, A., O’Neal, S., Machado, P. R. L., Guimarães, L. H., Morgan, D. J., Schriefer, A., et al. (2009). Association of treatment of American cutaneous Leishmaniasis prior to ulcer development with high rate of failure in northeastern Brazil. Am. J. Trop. Med. Hyg. 80, 574-579. 
Vanaerschot, M., Dumetz, F., Roy, S., Ponte-Sucre, A., Arevalo, J., and Dujardin, J. C. (2018). Treatment failure in Leishmaniasis: drug-resistance or another (epi-) phenotype? Expert Rev. Anti Infect. Ther. 12, 937-946. doi: 10.1586/ 14787210.2014 .916614

Vasconcellos, E. C. F., Schubach, A. O., Valete-Rosalino, C. M., Coutinho, R. S., Conceição-Silva, F., Salgueiro, M. M., et al. (2010). American tegumentary Leishmaniasis in older adults: 44 cases treated with an intermittent low-dose antimonial schedule in Rio de Janeiro, Brazil. J. Am. Geriatr. Soc. 58, 614-616. doi: 10.1111/j.1532-5415.2010.02747.x

Vera, L. A., Santos, J. B., Macêdo, V. D. O., Magalhães, A. V. D., Ciuffo, I. A., and Santos, C. G. (2001). Evaluation of the secondary bacterial infection's influence on the evolution of cutaneous Leishmaniasis in Corte de Pedra, Bahia. Rev. Soc. Bras. Med. Trop. 34, 233-237. doi: 10.1590/S0037-86822001000300001

Verma, P., Grover, G., and Sharma, S. (2014). Post-kala-azar dermal Leishmaniasis in pregnancy: hitherto unaccounted. Int. J. Dermatol. 53, 1501-1504. doi: 10. 1111/j.1365-4632.2012.05810.x

Viana da Costa, A., Huerre, M., Delacre, M., Auriault, C., Costa, J. M. C., and Verwaerde, C. (2002). IL-10 leads to a higher parasite persistence in a resistant mouse model of Leishmania major infection. Parasitol. Int. 51, 367-379. doi: 10.1016/S1383-5769(02)00039-9

Weinberger, B., Herndler-Brandstetter, D., Schwanninger, A., Weiskopf, G., and Grubeck-Loebenstein, B. (2008). Biology of immune responses to vaccines in elderly persons. Clin. Infect. Dis. 46, 1078-1084. doi: 10.1086/529197

World Health Organization [WHO] (2017a). Global Leishmaniasis update, 20062015: a turning point in Leishmaniasis surveillance. Wkly. Epidemiol. Rec. 38, $557-572$.
World Health Organization [WHO] (2017b). "Malnutrition". Last Modified May, 2017. Available at: http://www.who.int/mediacentre/factsheets/ malnutrition/en/

Yurchenko, E., Tritt, M., Hay, V., Shevach, E. M., Belkaid, Y., and Piccirillo, C. A. (2006). CCR5-dependent homing of naturally occurring CD4+ regulatory $\mathrm{T}$ cells to sites of Leishmania major infection favors pathogen persistence. J. Exp. Med. 203, 2451-2460. doi: 10.1084/jem.20060956

Zangger, H., Hailu, A., Desponds, C., Lye, L.-F., Akopyants, N. S., Dobson, D. E., et al. (2014). Leishmania aethiopica field isolates bearing an endosymbiontic DsRNA virus induce pro-inflammatory cytokine response. PLoS Negl. Trop. Dis. 8:e2836. doi: 10.1371/journal.pntd.0002836

Ziaie, H., and Sadeghian, G. (2008). Isolation of bacteria causing secondary bacterial infection in the lesions of cutaneous Leishmaniasis. Indian J. Dermatol. 53, 129-131. doi: 10.4103/0019-5154.43217

Conflict of Interest Statement: The authors declare that the research was conducted in the absence of any commercial or financial relationships that could be construed as a potential conflict of interest.

Copyright (c) 2018 Conceição-Silva, Leite-Silva and Morgado. This is an open-access article distributed under the terms of the Creative Commons Attribution License (CC BY). The use, distribution or reproduction in other forums is permitted, provided the original author(s) and the copyright owner are credited and that the original publication in this journal is cited, in accordance with accepted academic practice. No use, distribution or reproduction is permitted which does not comply with these terms. 